Chronique bibliographique : Les publications récentes (2008-2010) sur la Préhistoire et l'archéologie historique de la Basse-Normandie

\title{
Anne Ropars
}

\section{CpenEdition}

\section{Journals}

Édition électronique

URL : http://journals.openedition.org/rao/1463

DOI : $10.4000 /$ rao. 1463

ISBN : 978-2-7535-1846-9

ISSN : $1775-3732$

Éditeur

Presses universitaires de Rennes

\section{Édition imprimée}

Date de publication : 31 décembre 2011

Pagination : 246-268

ISBN : 978-2-7535-1844-5

ISSN : 0767-709X

\section{Référence électronique}

Anne Ropars, «Chronique bibliographique : Les publications récentes (2008-2010) sur la Préhistoire et l'archéologie historique de la Basse-Normandie », Revue archéologique de l'Ouest [En ligne], 28 | 2011 mis en ligne le 30 mars 2012, consulté le 06 décembre 2020. URL : http://journals.openedition.org/ rao/1463 ; DOI : https://doi.org/10.4000/rao.1463 


\title{
Chronique bibliographique Les publications récentes (2008-2010) sur la Préhistoire et l'archéologie historique de la Basse-Normandie
}

\author{
Anne Ropars*
}

Les publications du premier semestre 2008 ont été référencées dans la précédente chronique bibliographique (2006-2008) de la $R A O, 25$, p. $345-357$

\section{GÉNÉralités et pUblications DIACHRONIQUES}

ARANDA, R., ZAOUR, N., LEPAUMIER, H., 2009 Vers une nouvelle technique de réduction en ventilation naturelle : les fours à sole perforée. Les Nouvelles de l'Archéologie, 116, p. 28-32.

BERNARD, V., BILLARD, C., BOUFFIGNY, A., LEDIGOL, Y., 2008 - Un point sur la datation des vestiges de pêcheries de la façade occidentale du département de la Manche. Revue de la Manche, 50, fasc. 201, p. 34-37.

BILLARD, C., BERNARD, V., BOUFFIGNY, A., LEDIGOL, Y., 2009 - La datation des vestiges de pêcheries de la façade occidentale du département de la Manche. Bulletin du groupe de recherches archéologiques du Cotentin, 13, p. 34-35.

CARPENTIER, V., 2008 - La basse Dives et ses riverains des origines aux temps modernes : archéologie environnementale des zones humides et littorales. Archéopages, 23, p. 6-11.

CARPENTIER, V., MARCIGNY, C., 2008 - Des hommes aux champs. L'Archéologue, Archéologie nouvelle, 97, p. $40-43$.

CARPENTIER, V., 2009 - La consommation des produits de la mer : quelques données archéologiques récentes en Basse-Normandie. Archéopages, 26, p. 6-15.
CARPENTIER, V., 2010 - La Hague aux périodes historiques. In, MARCIGNY C. (dir.), La Hague dans tous ses états. Archéologie, Histoire, Anthropologie. OREP Éditions, p. 114-129.

CHEVALIER, A., 2009 - Espaces funéraires et réseaux viaires protohistoriques en Basse-Normandie. Deux approches mathématiques de l'espace. Les Nouvelles de l'Archéologie, 115, p. 44-51.

CLIQUET, D., 2010 - Archéologie : mode d'emploi. OREP Éditions, $49 \mathrm{p}$.

CLIQUET, D., GHESQUIÈRE, E., 2010 - La Préhistoire dans la Hague. In, MARCIGNY C. (dir.), La Hague dans tous ses états. Archéologie, Histoire, Anthropologie. OREP Éditions, p. 68-83.

COLLECTIF, 2010 - Bilan scientifique régional 2009. Ministère de la Culture et de la Communication, Direction régionale des Affaires culturelles de BasseNormandie, service régional de l'archéologie, $154 \mathrm{p}$.

COUTARD, J.-P., CLIQUET, D., LÉCOLLE, F., 2010 Jean-Pierre Lautridou (1938-2010). Quaternaire, 21/4, p. 341-344.

DUJARDIN, L. , 2010 - Le commerce de la pierre de Caen (XI ${ }^{\mathrm{e}} \mathrm{XVIII}^{\mathrm{e}}$ siècle). In, ARNOUX M., FLAMBARDHÉRICHER A.-M. (dir.), La Normandie dans l'économie européenne (XII-XVII siècle), (Actes du colloque de Cerisyla-Salle, 4-8 octobre 2006). Publications du CRAHM, p. 139-152.

DUPRET, L., 2010 - Les pierres de la Hague, témoins de deux milliards d'années d'histoire de la Terre. In, MARCIGNY C. (dir.), La Hague dans tous ses états. Archéologie, Histoire, Anthropologie. OREP Éditions, p. 28-37. 
FERRETTE, R., SIMON, L., 2010 - Le site du Petit Parc à Ménil-Froger (Orne) de la Préhistoire à la villa galloromaine. Revue Archéologique de l'Ouest, 27.

FICHET DE CLAIRFONTAINE, F., 2010 - Un bilan et des perspectives. In, Bilan de la Recherche Archéologique Basse-Normandie 1984-2010: Du Paléolithique à la fin de l'Age du Fer - Vol. I : Préhistoire - Protohistoire. Ministère de la Culture et de la Communication, p. 169-176.

HULIN, G., NORMANT, S., 2008 - Prospection aérienne des marais du Cotentin et du Bessin. Revue de la Manche, 50, fasc. 200, p. 42-44.

HULIN, G., NORMANT, S., 2009 - Prospection aérienne des marais du Cotentin et du Bessin. Bulletin du groupe de recherches archéologiques du Cotentin, 13, p. 50-53.

JUHEL, L., 2008 - Feu et préhistoire dans le Cotentin. Le Viquet, 160, p. 3-4.

LAUTRIDOU, J.-P., CLIQUET, D., 2010 - La Pointe de la Hague : géomorphologie, géologie du Quaternaire et archéologie. In, MARCIGNY C. (dir.), La Hague dans tous ses états. Archéologie, Histoire, Anthropologie. OREP Éditions, p. 38-51.

LE CARLIER, C., 2010 - Analyses chimiques des objets à base cuivre : vers la recherche des signatures d'ateliers. In, MARCIGNY Cyril (dir.), La Hague dans tous ses états. Archéologie, Histoire, Anthropologie. OREP Éditions, p. 97.

LE CARLIER, C., MARCIGNY, C., 2010 - Dépôts de bronze, pratiques sociales et rituelles de l'âge du Bronze à l'âge du Fer en Normandie. L'Archéologue, Revue d'archéologie et d'histoire, 111, décembre 2010-janvier 2011, p. 35-38.

LECLERC, G., 2010 - Cerisé : des origines à la fin de la Gaule Romaine. Bulletin de la Société Historique et Archéologique de l'Orne, CXXIX, 1-2, p. 16-24.

LEROUVILLOIS, R., 2010 - Historique des recherches dans la Hague du XviII ${ }^{\mathrm{e}}$ siècle à l'après-guerre. In, MARCIGNY C. (dir.), La Hague dans tous ses états. Archéologie, Histoire, Anthropologie. OREP Éditions, p. 16-27.

LESPEZ, L., CADOR, J.-M., CARPENTIER, V., CLETPELLERIN, M., GERMAINE, M.-A., GARNIER, E., MARCIGNY, C., 2008 - Trajectoire des paysages des vallées normandes et gestion de l'eau, du Néolithique aux enjeux de la gestion contemporaine. In, GALOP D. (dir.), Paysage et environnement : de la reconstitution $d u$ passé aux modèles prospectifs. Besançon, Presses universitaires de Franche-Comté, (Annales littéraires de FrancheComté, série Environnement, Société et archéologie), p. 61-75.

LESPEZ, L., CLET-PELLERIN, M., LIMONDINLOZOUET, N., PASTRE, J.-F., FONTUGNE, M.,
MARCIGNY, C., 2008 - Fluvial system evolution and environmental changes during the Holocene in the Mue valley (W France). Geomorphology, 98, 1-2, p. 55-70.

LESPEZ, L., BALLOUCHE, A., 2009 - L'objet, le sensible et leurs trajectoires. In, Paysages au fil de l'eau. Bulletin de l'Association de Géographes Français, 1, p. 3-11.

LESPEZ, L., MENESSON, B., DAVIDSON, R., DESMAREST, T., MARCIGNY, C., 2009 - La part de la nature dans le développement des plaines littorales de la Hague. In, MARCIGNY C. (dir.), Archéologie, histoire et anthropologie de la presquîle de la Hague (Manche). Analyse sur la longue durée d'un espace naturel et social cohérent. Quatrième année de recherche, 2008. p. 12-17.

LESPEZ, L., 2010 - Environnement et paysages dans la péninsule de la Hague depuis le Néolithique. In, MARCIGNY C. (dir.), La Hague dans tous ses états. Archéologie, Histoire, Anthropologie. OREP Éditions, p. 52-67.

LESPEZ, L., CLET-PELLERIN, M., DAVIDSON, R., HERMIER, G., CARPENTIER, V., CADOR, J.-M., 2010 - Middle to Late Holocene landscape changes and geoarchaeological implications in the marshes of the Dives estuary (NW France). Quaternary International, 216, p. 23-40.

LEVALET, D., 2010 - Nouvelles découvertes archéologiques à Avranches. Revue de l'Avranchin et du Pays de Granville, 87, fasc. 422, p. 101-106.

MARCIGNY, C., 2008 - Archéologie, histoire et anthropologie de la presquîle de la Hague (Manche). Analyse sur la longue durée d'un espace naturel et social cohérent. Troisième année de recherche, 2007. Beaumont-Hague, $100 \mathrm{p}$.

MARCIGNY, C., 2009 - Archéologie, Histoire et Anthropologie de la presqu'île de la Hague (Manche). Analyse sur la longue durée d'un espace naturel et social cohérent. Quatrième année de recherche, 2008. Beaumont-Hague, $152 \mathrm{p}$.

MARCIGNY, C. (dir.), 2010 - La Hague dans tous ses états. Archéologie, Histoire, Anthropologie. OREP Éditions, 160 p.

MARCIGNY, C., 2010 - Les recherches archéologiques dans la Hague. In, MARCIGNY C. (dir.), La Hague dans tous ses états. Archéologie, Histoire, Anthropologie. OREP Éditions, p. 10-15.

ROSE, Y., 2009 - Archéologie et Urbanisme : concilier passé et futur? L'exemple d'Alençon. Bulletin de la Société des Antiquaires de Normandie, 67, (2008), p. 289-302.

SERRAND, N., DUPONT, C., MARTIN, C., 2008 L'archéomalacologie : apport de l'étude des restes de mollusques à l'interprétation des sites archéologiques. Archéopages, 22, p. 62-75. 
THIÉBAULT, S., 2010 - Archéologie environnementale de la France. La Découverte, (Archéologies de la France), $177 \mathrm{p}$.

VAN DEN BOSSCHE, B., CARPENTIER, V., MARCIGNY, C., 2009 - Évolution des formes de l'exploitation agricole dans la campagne normande (250030 avant J.-C.) : l'exemple des fouilles préventives de la périphérie sud de Caen. Revue Archéologique de l'Ouest, 26, p. 57-83.

VAN DEN BOSSCHE, B., MARCIGNY, C., 2008 - Changing settlement patterns in the Normandy countryside. In, FAVORY François, NUNINGER Laure (dir.), Colloque ArchaeDyn, Dijon p. 175-186

VILGRAIN-BAZIN, G., DESHAYES, J., JUHEL, L., 2008 - Nord-Cotentin, les occupations littorales, prospections diachroniques. Revue de la Manche, 50, fasc. 201, p. 49-52.

VILGRAIN-BAZIN, G., JUHEL, L., DESHAYES, J., YVON, J.-M., 2009 - Les occupations littorales dans le Nord-Cotentin. Bulletin du groupe de recherches archéologiques du Cotentin, 13, p. 61-62.

\section{Paléolithique - Mésolithique}

ARTUR, E., BILLARD, C., 2008 - Les occupations du Mésolithique final de Biéville-Beuville "Le Vivier" (Calvados). Revue Archéologique de l'Ouest, 25, p. 53-92.

CLIQUET, D., 2008 - Le site pléistocène moyen récent de Ranville (Calvados - France) dans son contexte environnemental : analyse du fonctionnement d'une aire de boucherie soutirée par un résean karstique. Liège, Université de Liège, 211 p. (ERAUL).

CLIQUET, D., 2008 - Les premiers hommes en Normandie. Revue de la Manche, 50, fasc. 202, p. 37-45.

CLIQUET, D., 2009 - P.C.R. "Les premiers hommes en Normandie ". Bulletin du groupe de recherches archéologiques du Cotentin, 13, p. 15-19.

CLIQUET, D., MERCIER, N., LAUTRIDOU, J.-P., ALIX, P., BEUGNIER, V., BIANCHINI, R., CASPAR, J.-P., COUTARD, S., LASSEUR, É., LORREN, P., GOSSELIN, R., RIVARD, J.-J., VALLADAS, H., 2009 - Un atelier de production et de consommation d'outils bifaciaux de la fin du Paléolithique moyen à Saint-Brice-Sous-Rânes (Orne - France) dans son contexte environnemental. Quaternaire, 20-3, p. 361379.

CLIQUET, D., LAUTRIDOU, J.-P., COUTARD, J.-P., COUTARD, S., VILGRAIN-BAZIN, G., 2009 Digulleville "Jardeheu ": un habitat en bordure de plaine littorale. In, MARCIGNY C. (dir.), Archéologie, histoire et anthropologie de la presqu'île de la Hague (Manche). Analyse sur la longue durée d'un espace naturel et social cohérent. Quatrième année de recherche, 2008. Beaumont-Hague, p. 18-23.

CLIQUET, D., LAUTRIDOU, J.-P., LAMOTHE, M., MERCIER, N., SCHWENNINGER, J.-L., ALIX, P., VILGRAIN-BAZIN, G., 2009 - Nouvelles données sur le site majeur d'Ecalgrain : datations radiométriques et occupations humaines de la pointe de la Hague (Cotentin, Normandie). Quaternaire, 20-3, p. 345-359.

CLIQUET, D., LAUTRIDOU, J.-P., 2009 - Les occupations humaines du Pléistocène moyen de Normandie dans leur cadre environnemental. Quaternaire, 20-3, p. 305-320.

CLIQUET, D., GHESQUIÈRE, E., 2010 - Le Paléolithique et le Mésolithique en Basse-Normandie $(-350000$ à -5100 av. J.-C.) : bilan de la recherche 1984-2004. In, Bilan de la Recherche Archéologique BasseNormandie 1984-2010: Du Paléolithique à la fin de l'Age du Fer-Vol. I: Préhistoire - Protohistoire. Ministère de la Culture et de la Communication, p. 11-54.

GHESQUIÈRE, E., VILGRAIN-BAZIN, G., 2009 - Étude de la série lithique de Vasteville «La Fosse à Loup ». In, MARCIGNY C. (dir.), Archéologie, histoire et anthropologie de la presqu'ile de la Hague (Manche). Analyse sur la longue durée d'un espace naturel et social cohérent. Quatrième année de recherche, 2008. Beaumont-Hague, p. 24-35.

GHESQUIÈRE, E., MARCHAND, G., 2010 - Le Mésolithique en France : Archéologie des derniers chasseurscueilleurs. Paris, La Découverte, 177 p.

GHESQUIÈRE, E., 2010 - Sondages sur un site mésolithique du Nord-Cotentin : Jobourg "Perréval 2" (Manche). Revue Archéologique de l'Ouest, 27.

GHESQUIËRE, E., 2010 - Une fosse (de stockage?) du Mésolithique récent à Ronai "La Grande Bruyère " (Orne, Basse-Normandie). Bulletin de la Société Préhistorique Française, 107, 3, p. 595-596.

LECLERC, F., 2008 - Recherche sur l'origine des matières premières utilisées par les premiers hommes dans le secteur de Siouville. Revue de la Manche, 50, fasc. 202, p. 46-53.

LECLERC, F., 2009 - Recherche sur l'origine des matières premières utilisées par les premiers hommes. Bulletin du groupe de recherches archéologiques du Cotentin, 13, p. 29-33.

LORIEUX, J.-C., 2008 - Avec 30000 ans de retard, CroMagnon s'aventure en terre normande. Au Fil de la Normandie, 20, p. 40-41. 
LORIEUX, J.-C., 2008 - Normands des cavernes ou le règne de Néandertal. Au Fil de la Normandie, 20, p. 38-39.

LORIEUX, J.-C., 2008 - Mésolithique : les beaux jours des chasseurs-cueilleurs. Au Fil de la Normandie, 20, p. 46-47.

MARCHAND, G., MICHEL, S., 2009 - L'essart et le Mésolithique dans le centre ouest de la France. In, Des feux dans la vallée: les habitats du Mésolithique et du Néolithique récent de l'essart à Poitiers. Rennes, PUR, coll. "Archéologie et Culture », p. 181-210.

MASSON, B., 2010 - Structures de combustion et structures périglaciaires. Réexamen taphonomique des structures de combustion moustériennes de Saint-Vaastla-Hougue (50) [en ligne]. In, THÉRY-PARISOT I. CHABAL L. \& Costamagno S. (eds.), Taphonomie des résidus organiques brûlés et des structures de combustion en milieu archéologique, (Actes de la table ronde, Valbonne, 27-29 mai 2008). P@lethnologie.org. Revue bilingue de Préhistoire, 2, p. 5-23. [http://www.palethnologie.org/revue.php]

MICHEL, S., 2009 - Le Premier Mésolithique du CentreOuest : modalités techniques de l'industrie lithique. Bulletin de la Société Prébistorique Française, 106, $\mathrm{n}^{\circ} 4$, p. 715-734.

\section{NÉOLITHIQUe}

BEDAULT, L., HACHEM, L., 2008 - Recherches sur les sociétés du Néolithique danubien à partir du Bassin parisien : approche structurelle des données archéozoologiques. In, BURNEZ-LANOTTE L., ILETT M., ALLARD P., (dir.), Fin des traditions danubiennes dans le Néolithique du Bassin parisien et de la Belgique (51004700 BC), (Colloque international, Namur, 24-25 novembre 2006). Paris, Société préhistorique française, (Mémoire de la Société préhistorique française; XLIV), p. 221-243.

BERNAGE, G., 2009 - Les premiers paysans en Normandie. Patrimoine Normand, 70, p. 40-47.

BERNARD, V., 2010 - Chemins et routes de tourbières à la charnière des Ve et IVe millénaires. L'archéo Thema, Revue d'archéologie et d'histoire, 10, septembre-octobre, p. 25.

BILLARD, C., BERNARD, V., BOUFFIGNY, A., LEDIGOL, Y., QUÉVILLON, S., 2010 - Barrages à poissons : sources documentaires et problématiques sur les pêcheries fixes pré- et protohistoriques. In, BILLARD C., LEGRIS M. (dir.), Premiers Néolithiques de l'Ouest: cultures, réseaux, échanges des premières sociétés néolithiques à leur expansion, (Actes du colloque interrégional sur le Néolithique, Le Havre 2007). Rennes, PUR, coll. "Archéologie \& Culture », p. 377-399

BILLARD, C., GUILLON, M., VERRON, G., 2010 - Les sépultures collectives du Néolithique récent-final de Val-deReuil et Portejoie (Eure - France). Liège, Eraul, (ERAUL 123). $408 \mathrm{p}$.

CHAMBON, P., LECLERC, J., 2008 - Les pratiques funéraires. In, ALIX Nicole (dir.), Archéologie de la France : le Néolithique. Paris, Picard/Ministère de la culture et de la communication, p. 308-324.

CLÉMENT-SAULEAU，S., GHESQUIÈRE, E., GIAZZON, D., GIAZZON, S., MARCIGNY, C., PALLUAU, J.-M., VIPARD, L., 2010 - L'enceinte néolithique moyen de St-Martin-de-Fontenay « Le Diguet " (Calvados) : présentation liminaire. Internéo, 8, p. 71-79.

D’ANNA, A., GILIGNY, F., TINEVEZ, J.-Y., 2008 La céramique. In, ALIX Nicole (dir.), Archéologie de la France : le Néolithique. Paris, Picard/Ministère de la culture et de la communication, p. 239-282.

DESLOGES, J., GHESQUIÈRE, E., MARCIGNY, C., 2010 - La minière Néolithique ancien/moyen I des Longrais à Soumont-Saint-Quentin (Calvados). Revue Archéologique de l'Ouest, 27.

DRON, J.-L., 2010 - Condé-sur-Ifs (Calvados). De l'intérêt des datations radio-carbone. L'archéo Thema, Revue d'archéologie et d'histoire, 10, septembre-octobre, p. 16.

DRON, J.-L., GERMAIN-VALLÉE, C., CLÉMENTSAULEAU, S., GÂCHE, D., CHARRAUD, F., FROMONT, N., 2010 - La Bruyère du Hamel à Condésur-Ifs (Calvados) : un site entre Néolithique ancien et Néolithique moyen. In, BILLARD C., LEGRIS M. (dir.), Premiers Néolithiques de l'Ouest: cultures, réseaux, échanges des premières sociétés néolithiques à leur expansion, (Actes du colloque interrégional sur le Néolithique, Le Havre 2007). Rennes, PUR, coll. " Archéologie \& Culture », p. 163-179.

FOSSE, G., VILGRAIN-BAZIN, G., 2009 - Le site de Jardeheu à Digulleville : diachronie des occupations et foyers néolithiques. In, MARCIGNY C. (dir.), Archéologie, histoire et anthropologie de la presquî̀le de la Hague (Manche). Analyse sur la longue durée d'un espace naturel et social cohérent. Quatrième année de recherche, 2008. Beaumont-Hague, p. 36-45.

FROMONT, N., 2008 - Résultats préliminaires d'une fouille menée sur deux ensembles néolithiques présumés funéraires à Saint-Sylvain (Calvados). Internéo, 7 , p. 173-181.

FROMONT, N., MARCIGNY, C., 2008 - Acquisition, transformation et diffusion du schiste du Pissot au Néolithique ancien dans le quart nord-ouest de la France. 
In, BURNEZ-LANOTTE L., ILETT M., ALLARD P. (dir.), Fin des traditions danubiennes dans le Néolithique du Bassin parisien et de la Belgique (5100-4700 BC). Colloque international, Namur, 24-25 novembre 2006. (Mémoire de la Société Préhistorique Française; XLIV), p. 413-424.

FROMONT, N., HÉRARD, A., HÉRARD, B., 2009 - Un dépôt d'anneaux en schiste à Falaise "ZAC Expansia " (Calvados) ?. Bulletin de la Société Préhistorique Française, 106, n 2, p. 380-383.

GHESQUIÈRE, E., DESLOGES, J., MARCIGNY, C., CHARRAUD, F., 2008 - La production de lames en silex bathonien dans la plaine de Caen : redécouverte de la minière des Longrais à Soumont-Saint-Quentin (Calvados). Internéo, 7, p. 103-110.

GHESQUIÈRE, E., MARCIGNY, C. , 2008 - Le Néolithique ancien dans le Nord Ouest de la France. Archéopages, Hors série, p. 55-59.

GHESQUIÊRE, E., GIAZZON, D., MARCIGNY, C., 2010 - Habitats ceinturés en Normandie. L'enceinte néolithique de Goulet (Orne). L'archéo Thema, Revue d'archéologie et d'histoire, 10, septembre-octobre, p. 38-45.

GHESQUIÈRE, E., MARCIGNY, C., 2010 - L'allée couverte de Vauville. In, MARCIGNY C. (dir.), La Hague dans tous ses états. Archéologie, Histoire, Anthropologie. OREP Éditions, p. 95.

JUHEL, L., MARCIGNY, C., 2008 - Les occupations du Néolithique moyen de l'abri sous roche de la Jupinerie (Omonville-la-Petite, Manche). Revue de la Manche, 50, fasc. 200, p. 45-59.

JUHEL, L., GHESQUIÈRE, E., MARCIGNY, C., avec la coll. de CASPAR, J.-P., CLEMENT-SAULEAU, $S$. et LESPEZ, L., 2009 - Les occupations du Néolithique moyen de l'abri sous roche de la Jupinerie (Omonvillela-Petite - Manche). Bulletin du groupe de recherches archéologiques du Cotentin, 13, p. 20-28.

JUHEL, L., 2010 - Le Néolithique dans la Hague. In, MARCIGNY C. (dir.), La Hague dans tous ses états. Archéologie, Histoire, Anthropologie. OREP Éditions, p. 84-95.

KERDIVEL, G., HAMON, G., 2010 - Des dépôts spectaculaires en fosse sur l'éperon de Banville en Normandie. L'archéo Thema, Revue d'archéologie et d'histoire, 10, septembre-octobre, p. 46.

KERDIVEL, G., HAMON, G., avec la coll. de BARG, E J., BOHARD, B., DESLOGES, J., LEPAUMIER, H., 2010 - Un site du Néolithique moyen, du Néolithique final et de l'Âge du Fer à la Burette à Banville (Calvados) : présentation liminaire. In, BILLARD C., LEGRIS M. (dir.), Premiers Néolithiques de l'Ouest : cultures, réseaux, échanges des premières sociétés néolithiques à leur expansion, (Actes du colloque interrégional sur le Néolithique, Le Havre 2007). Rennes, PUR, coll. «Archéologie \& Culture, p. 211-235.

LE MAUX, N., 2010 - Les lames de hache polies en roches tenaces et en grès-quartzite de la Basse vallée de la Seine (de Paris au Havre). In, BILLARD C., LEGRIS M. (dir.), Premiers Néolithiques de l'Ouest : cultures, réseaux, échanges des premières sociétés néolithiques à leur expansion, (Actes du colloque interrégional sur le Néolithique, Le Havre 2007). Rennes, PUR, coll. «Archéologie \& Culture ", p. 237-271.

LEVALET, D., 2010 - Saint-Cyr-du-Bailleul. Revue de l'Avranchin et du Pays de Granville, 87, fasc. 424, p. $402-$ 405.

LORIEUX, J.-C., 2008 - Mégalithes : quand l'homme devient mégalo. Au Fil de la Normandie, 20, p. 50-51.

LORIEUX, J.-C., 2008 - Premières industries? L'exploitation minière des haches par million! Au Fil de la Normandie, 20, p. 52-53.

LORIEUX, J.-C., 2008 - La révolution néolithique : les premiers paysans en Normandie. Au Fil de la Normandie, 20, p. 48-49.

MARCHAND, G., MENS, E., CARRION MARCO, Y., BERTHAUD, G., KERDIVEL, G., GEORGE, E., QUESNEL, L., VISSAC, C., 2009 - Creuser puis brûler : foyers et carrières néolithiques de Mazières-enMauges "Le Chemin Creux » (Maine-et-Loire). Bulletin de la Société Préhistorique Française, 106, nº 4, p. $735-$ 759.

MARCIGNY, C., 2008 - Premières données sur la silexière de Ri/Ronai. Archéopages, 22, p. 14-15.

MARCIGNY, C., RIQUIER, V., 2009 - Les sites à « fosses en $\mathrm{V}-\mathrm{Y}$ " : émergence d'une problématique et d'un réseau au niveau national. Archéopages, 25, p. 70-77.

MARCIGNY, C., 2010 - Calvados. Une nouvelle enceinte du Néolithique moyen à St-Martin-de-Fontenay. L'Archéologue, Revue d'archéologie et d'histoire, 109, aoûtseptembre, p. 8.

MARCIGNY, C., GHESQUIÈRE, E., JUHEL, L., CHARRAUD, F., 2010 - Entre Néolithique ancien et Néolithique moyen en Normandie et dans les Iles anglonormandes : parcours chronologique. In, BILLARD C., LEGRIS M. (dir.), Premiers Néolithiques de l'Ouest : cultures, réseaux, échanges des premières sociétés néolithiques à leur expansion, (Actes du colloque interrégional sur le Néolithique, Le Havre 2007). Rennes, PUR, coll. "Archéologie \& Culture », p. 117-162.

PAILLER, Y., MARCHAND, G., BLANCHET, S., GUYODO, J.-N., HAMON, G., 2008 - Le VilleneuveSaint-Germain dans la péninsule Armoricaine : les 
débuts d'une enquête. In, BURNEZ-LANOTTE L., ILETT M., ALLARD P. (dir.), Fin des traditions danubiennes dans le Néolithique du Bassin parisien et de la Belgique (5100-4700 BC). (Colloque international, Namur, 24-25 novembre 2006). Paris, Société préhistorique française, (Mémoire de la Société préhistorique française; XLIV), p. 91-111.

SALANOVA, L., 2008 - Techniques décoratives et périodisations céramiques en contexte non rubané. In, BURNEZ-LANOTTE L., ILETT M., ALLARD P. (dir.), Fin des traditions danubiennes dans le Néolithique du Bassin parisien et de la Belgique (5100-4700 BC). (Colloque international, Namur, 24-25 novembre 2006). Paris, Société préhistorique française, (Mémoire de la Société préhistorique française; XLIV), p. 181-188.

VERRON, G., BILLARD, C., DESLOGES, J., DRON, J.-L., FROMONT, N., GHESQUIÈRE, E., JUHEL, L., MARCIGNY, C., 2010 - Le Néolithique en BasseNormandie (-5 100 à $-2300 /-2000$ av. J.-C.). Bilan de la Recherche 1984-2004. In, Bilan de la Recherche Archéologique Basse-Normandie 1984-2010: Du Paléolithique à la fin de l'Age du Fer - Vol. I: Préhistoire - Protohistoire. Ministère de la Culture et de la Communication, p. 55-92.

VILGRAIN-BAZIN, G., FOSSE, G., 2010 - Les foyers néolithiques de Jardeheu - la Gravette à Digulleville. In, MARCIGNY C. (dir.), La Hague dans tous ses états. Archéologie, Histoire, Anthropologie. OREP Éditions, p. 87.

WATTÉ, J.-P., 2008 - Progrès récents de la préhistoire en Normandie. Bulletin de la Société des Antiquaires de Normandie, LXV (2002-2003), p. 265-292.

WATTÉ, J.-P., MARTIN, B., 2008 - A propos d'objets préhistoriques provenant de Frénouville. Bulletin de la Société des Antiquaires de Normandie, LXV (2002-2003), p. 255-263.

\section{4. ÂGE DU BRONZE}

BAUDRY-DAUTRY, A., 2009 - L'élevage et l'alimentation à la fin de l'âge du Bronze et au premier âge du Fer dans l'ouest de la France : approche archéozoologique de quelques sites normands. In, ROULIERE-LAMBERT M.-J., DAUBIGNEY A., MILCENT P.-Y., TALON M., VITAL J. (dir.), De l'Âge du Bronze à l'Âge du Fer en France et en Europe occidentale ( $X^{e}-V I I^{e}$ siècle av. J.-C.) : la moyenne vallée du Rhône aux âges du Fer, (Actes du $\mathrm{XXX}^{\mathrm{e}}$ colloque international de l'AFEAF, Saint-Romainen-Gal, 26-28 mai 2006). Dijon, Société archéologique de l'est, (Revue archéologique de l'est, supplément; 27), p. 487-491.
BILLARD, C., DELRIEU, F., LAISNÉ, G., ROPARS, A., 2009 - État des lieux et actualité de la recherche sur les sites de hauteur de la Manche. Bulletin du groupe de recherches archéologiques du Cotentin, 13, p. 36-38.

BRIARD, J., 2009 - L'Âge du Bronze Atlantique, actualisation. Haute-Normandie archéologique, 14, p. 107-114.

CAROZZA, L., MARCIGNY, C., TALON, M., 2009 Ordres et désordres de l'économie des sociétés durant l'Âge du Bronze en France. In BARTELHEIM (M.), STAUBLE (H.) ed.- Die wirtschaftlichen grundlagen der Bronzezeit europas, The economic foundations of The European Bronze Age, Forschungen zur Archäometrie und Altertumswissenschaft, band 4. p. 23-65.

CHEVALIER, A., 2009 - Espaces funéraires et réseaux viaires protohistoriques en Basse-Normandie. Deux approches mathématiques de l'espace. Les Nouvelles de l'Archéologie, 115, p. 44-51.

DELRIEU, F., 2008 - Igé : le point des connaissances sur le "Crochemélier » (Orne). Cahiers Percherons, 176, 4e trimestre, p. 43-53.

DELRIEU, F., BILLARD, C., LAISNÉ, G., ROPARS, A., 2008 - État des lieux et actualités de la recherche sur les sites de hauteur de la Manche. Revue de la Manche, 50, fasc. 201, p. 39-42.

DELRIEU, F., avec la coll. de COUTARD, J.-P., 2009 Le tumulus de "Calais » à Jobourg. In, MARCIGNY C. (dir.), Archéologie, histoire et anthropologie de la presquîle de la Hague (Manche). Analyse sur la longue durée d'un espace naturel et social cohérent. Quatrième année de recherche, 2008. Beaumont-Hague, p. 46-61.

DELRIEU, F., 2009 - Les Tumulus dans la Hague (Manche). In, DELRIEU F. (dir.), Les Gaulois et la mort en Normandie, les pratiques funéraires à l'Âge du Fer (VII'$I^{e r}$ siècles avant J.-C.). Cully, Orep Éditions, p. 4-5.

DELRIEU, F., 2009 - Les Tumulus privilégiés du Bronze Ancien. In, DELRIEU F. (dir.), Les Gaulois et la mort en Normandie, les pratiques funéraires à l'Âge du Fer (VIT-- $\mathrm{I}^{\text {er }}$ siècles avant J.-C.). Cully, Orep Éditions, p. 3.

DELRIEU, F., 2010 - Le tumulus de "Calais " à Jobourg. In, MARCIGNY Cyril (dir.), La Hague dans tous ses états. Archéologie, Histoire, Anthropologie. OREP Éditions, p. 102-103.

GIRAUD, P., DELRIEU, F., 2009 - Les sites fortifiés protohistoriques de hauteur en Basse-Normandie. Nouvelles données pour l'âge du Bronze. Bulletin de l'Association pour la Promotion des Recherches sur l'âge du Bronze, 6, p. 33-35.

KRISTIANSEN, K., 2009 - Premières aristocraties : Pouvoir et métal à l'âge du Bronze. In, DEMOULE Jean-Paul (dir.), L'Europe, un continent redécouvert par l'archéologie. Paris, Gallimard, p. 72-83. 
LE CARLIER, C. et MARCIGNY, C., 2010 - Dépôts de bronze, pratiques sociales et rituelles de l'âge du Bronze à l'âge du Fer en Normandie, L'Archéologue, n 110 , décembre 2010-janvier 2011, p. 35-38.

MANEM, S., 2010 - Des habitats aux sites de rassemblement à vocation rituelle : l'âge du Bronze selon le concept de "chaîne opératoire ". Les Nouvelles de l'Archéologie, 119, p. 30-36.

MARCIGNY, C., 2008 - Du territoire immédiat au territoire culturel à l'âge du Bronze : quelques exemples de l'ouest de la France. Archéopages, 21, p. 22-29.

MARCIGNY, C., DELRIEU, F., 2008 - L'Âge du Bronze en Normandie : bilan des travaux 2007. Bulletin de l'Association pour la Promotion des Recherches sur l'âge du Bronze, 5, p. 65-68.

MARCIGNY, C., GHESQUIÈRE, E., 2008 - Espace rural et systèmes agraires dans l'ouest de la France à l'âge du Bronze : quelques exemples normands. In, GUILAINE Jean (dir.), Villes, villages, campagnes de l'âge du Bronze, séminaires du Collège de France. Éditions Errance, p. 256-278.

MARCIGNY, C., 2009 - L'âge du Bronze et l'arrivée des Celtes. Dossier : Normandie celte et romaine. L'Archéologue, Revue d'archéologie et d'histoire, 102, juinjuillet p. 12-14.

MARCIGNY, C., 2009 - Retour au " Hague Dike » : historiographie et nouvelles analyses. Annuaire des cinq départements de la Normandie, 166 ${ }^{\mathrm{e}}$ Congrès, p. 97-110.

MARCIGNY, C., GIAZZON, D., 2009 - Les enclos circulaires : Agneaux "La Tremblaye " (Manche). In, DELRIEU F. (dir.), Les Gaulois et la mort en Normandie, les pratiques funéraires à l'Âge du Fer (VII - - ${ }^{e r}$ siècles avant J.-C.). Cully, Orep Éditions, p. 6-7.

MARCIGNY, C., TALON, M., 2009 - Sur les rives de la Manche. Qu'en est-il du passage de l'âge du Bronze à l'âge du Fer à partir des découvertes récentes?. In, ROULIERE-LAMBERT M.-J., DAUBIGNEY A., MILCENT P.-Y., TALON M., VITAL J. (dir.), De l'Âge du Bronze à l'Âge du Fer en France et en Europe occidentale ( $X^{\mathrm{T}}$-VII siècle av. J.-C.) : la moyenne vallée du Rhône aux âges du Fer, (Actes du XXX colloque international de l'AFEAF, Saint-Romain-en-Gal, 26-28 mai 2006). Dijon, Société archéologique de l'est, (Revue archéologique de l'est, supplément; 27), p. 385-403.

MARCIGNY, C., SAVARY, X., VERNEY, A., VERRON, G., 2010 - L'âge du Bronze en Basse-Normandie $(-2300 /-2000$ à -800 av. J.-C.). Bilan de la Recherche 1984-2004. In, Bilan de la Recherche Archéologique BasseNormandie 1984-2010: Du Paléolithique à la fin de l'Age du Fer - Vol. I : Préhistoire - Protohistoire. Ministère de la Culture et de la Communication, p. 93-142.
MARCIGNY, C., 2010 - De l'âge du Bronze à l'âge du Fer dans la Hague. In, MARCIGNY C. (dir.), La Hague dans tous ses états. Archéologie, Histoire, Anthropologie. OREP Éditions, p. 96-113.

MARCIGNY, C., 2010 - Le Hague Dike. In, MARCIGNY C. (dir.), La Hague dans tous ses états. Archéologie, Histoire, Anthropologie. OREP Éditions, p. 107-108.

MILCENT, P.-Y., 2009 - Le passage de l'Âge du Bronze à l'Âge du Fer en Gaule au miroir des élites sociales : une crise au viII siècle av. J.-C.?. In, ROULIERE-LAMBERT M.-J., DAUBIGNEY A., MILCENT P.-Y., TALON M., VITAL J. (dir.), De l'Âge du Bronze à l'Âge du Fer en France et en Europe occidentale ( $X^{\top}-V I T$ siècle av. J.-C.) : la moyenne vallée du Rhône aux âges du Fer, (Actes du XXX colloque international de l'AFEAF, Saint-Romain-en-Gal, 26-28 mai 2006). Dijon, Société archéologique de l'est, (Revue archéologique de l'est, supplément; 27), p. 453-476.

NOËL, J.-Y., 2008 - In terra incognita : le Campaniforme normand, synthèse préliminaire du mobilier céramique. Bulletin de la Société Préhistorique Française, 105-3, p. 577-593.

NOËL, J.-Y., 2010 - Le début des âges des métaux : le campaniforme dans la Hague. In, MARCIGNY Cyril (dir.), La Hague dans tous ses états. Archéologie, Histoire, Anthropologie. OREP Éditions, p. 98.

\section{5. ÂGE DU FER}

BAUDRY, A., AUXIETTE, G., 2009 - Élevage, cheptel. In, GIRAUD P. (dir.), Gaulois sous les pommiers, découvertes de l'àge du Fer en Basse-Normandie, IXe-Ir siècle av. J.-C. Cabourg, Conseil Général du Calvados, service d'archéologie; Éditions Cahiers du Temps, p. 48-50.

BESNARD-VAUTERIN, C.-C. NAVARRE, N., 2008 Un habitat de la Tène finale à l'époque gallo-romaine sur la ZAC de Beaulieu à Caen (Calvados). Revue Archéologique de l'Ouest, 25, p. 163-186.

BESNARD-VAUTERIN, C.-C., 2009.- En plaine de Caen, une campagne gauloise et antique. L'occupation du site de l'Étoile à Mondeville. Rennes, PUR, coll. «Archéologie et Culture », $312 \mathrm{p}$.

BESNARD-VAUTERIN, C.-C., 2009.- Falaise, un habitat clos du second âge du Fer à Falaise «Expansia ». Dossier : Normandie celte et romaine. L'Archéologue, Revue d'archéologie et d'histoire, 102, juin-juillet p. 20-21.

BESNARD-VAUTERIN, C.-C., 2009 - Ifs " Object'Ifs Sud ", fouille 2008. In, DELRIEU F. (dir.), Les Gaulois et la mort en Normandie, les pratiques funéraires à l'Âge du Fer (VII-Tr siècles avant J.-C.). Cully, Orep Éditions, p. 19-20. 
BESNARD-VAUTERIN, C.-C., 2009 - Nécy " La Martinière »(Orne) : les sépultures isolées d'un habitat gaulois. In, DELRIEU F. (dir.), Les Gaulois et la mort en Normandie, les pratiques funéraires à l'Âge du Fer (VIte-Ier siècles avant J.-C.). Cully, Orep Éditions, p. 36.

BESNARD-VAUTERIN, C.-C., 2009 - Un habitat clos à Falaise "Expansia " (Calvados). In, GIRAUD P. (dir.), Gaulois sous les pommiers, découvertes de l'âge du Fer en Basse-Normandie, IX'-1er siècle av. J.-C. Cabourg, Conseil Général du Calvados, service d'archéologie; Éditions Cahiers du Temps, p. 29-30.

BESNARD-VAUTERIN, C.-C., JAHIER, I., LE GOFF, E., 2009 - Les structures de stockage. In, GIRAUD P. (dir.), Gaulois sous les pommiers, découvertes de l'âge du Fer en Basse-Normandie, $I X^{X}-I^{\text {er }}$ siècle av. J.-C. Cabourg, Conseil Général du Calvados, service d'archéologie; Éditions Cahiers du Temps, p. 60-63.

BLANCQUAERT, G. LORHO, T., MALRAIN, F., MENEZ, Y., 2009 - Bilan et perspectives de recherche sur les sites ruraux au second Âge du Fer. In, BERTRAND I., DUVAL A., GOMEZ DE SOTO J., MAGUER P. (dir.), Habitats et paysages ruraux en Gaule et regards sur d'autres régions du monde celtique, (Actes du XXXI e colloque interrégional de l'Association Française pour l'Étude de l'Âge du Fer, 17-20 mai 2007, Chauvigny - Vienne, F). Chauvigny, Association des publications chauvinoises, (Mémoire XXXV des publications chauvinoises). p. 5-23.

BLANCQUAERT, G., MALRAIN, F., avec la coll. de LORHO, T., 2009 - Un enclos = une ferme?. In, BERTRAND I., DUVAL A., GOMEZ DE SOTO J., MAGUER P. (dir.), Habitats et paysages ruraux en Gaule et regards sur d'autres régions du monde celtique, (Actes du XXXI e colloque interrégional de l'Association Française pour l'Étude de l'Âge du Fer, 17-20 mai 2007, Chauvigny - Vienne, F). Chauvigny, Association des publications chauvinoises, (Mémoire XXXV des publications chauvinoises). p. 25-43.

CARPENTIER, V., 2009 - Le sel gaulois. In, GIRAUD P. (dir.), Gaulois sous les pommiers, découvertes de l'âge du Fer en Basse-Normandie, IX'-Ir siècle av. J.-C. Cabourg, Conseil Général du Calvados, service d'archéologie; Éditions Cahiers du Temps, p. 78-80.

CHANSON, K., 2009 - La nécropole à incinérations d'Ifs (Calvados). In, GIRAUD P. (dir.), Gaulois sous les pommiers, découvertes de l'âge du Fer en Basse-Normandie, $I X-$ $i^{e r}$ siècle av. J.-C. Cabourg, Conseil Général du Calvados, service d'archéologie; Éditions Cahiers du Temps, p. 104-106.

CHANSON, K., 2009 - L'outillage agricole. In, GIRAUD P. (dir.), Gaulois sous les pommiers, découvertes de l'âge du
Fer en Basse-Normandie, $I X^{e}-\mathrm{I}^{\text {er }}$ siècle av. J.-C. Cabourg, Conseil Général du Calvados, service d'archéologie; Éditions Cahiers du Temps, p. 53-55.

CHEREL, A.-F., 2009 - La parure de l'incinération 1394 d'Ifs (Calvados). In, GIRAUD P. (dir.), Gaulois sous les pommiers, découvertes de l'àge du Fer en Basse-Normandie, $I X^{e}-I^{e r}$ siècle av. J.-C. Cabourg, Conseil Général du Calvados, service d'archéologie; Éditions Cahiers du Temps, p. 81.

CHEREL, A.-F., 2009 - La poterie. In, GIRAUD P. (dir.), Gaulois sous les pommiers, découvertes de l'âge du Fer en Basse-Normandie, $I X-X^{e} I^{r}$ siècle av. J.-C. Cabourg, Conseil Général du Calvados, service d'archéologie; Éditions Cahiers du Temps, p. 66-68.

DECHEZLEPRÊTRE, T., 2010 - La fortification de l'oppidum de Vernon dans son contexte régional. In, Murus Ceticus : Architecture et fonctions des remparts de l'âge du Fer, (Actes de la Table ronde internationale, 11-12 octobre, 2006, Glux-en-Glenne). Bibracte, 19, p. 145 166.

DELALANDE, A., 2009 - Évolution de la parure au premier âge du Fer. In, GIRAUD P. (dir.), Gaulois sous les pommiers, découvertes de l'àge du Fer en Basse-Normandie, $I X^{e}-I^{e r}$ siècle av. J.-C. Cabourg, Conseil Général du Calvados, service d'archéologie; Éditions Cahiers du Temps, p. 82-85.

DELRIEU, F., 2009 - Habitats et nécropoles, une relation de proximité. In, DELRIEU F. (dir.), Les Gaulois et la mort en Normandie, les pratiques funéraires à l'Âge du Fer (VII-Ier siècles avant J.-C.). Cully, Orep Éditions, p. 32.

DELRIEU, F., 2009 - Le Camp de Bierre à Merri (Orne). In, GIRAUD P. (dir.), Gaulois sous les pommiers, découvertes de l'âge du Fer en Basse-Normandie, $Z^{e}-\mathrm{I}^{\mathrm{r}}$ av. siècle J.-C. Cabourg, Conseil Général du Calvados, service d'archéologie; Éditions Cahiers du Temps, p. 38-41.

DELRIEU F., 2009 - Les nécropoles de la fin du 1er Âge du Fer et de la Tène ancienne. In, DELRIEU F. (dir.), Les Gaulois et la mort en Normandie, les pratiques funéraires à l'Âge du Fer (VIt-Itr siècles avant J.-C.). Cully, Orep Éditions, p. 9.

DELRIEU, F., 2009 - Nécropole de Nonant-le-Pin « La Garenne "(Orne). In, DELRIEU F. (dir.), Les Gaulois et la mort en Normandie, les pratiques funéraires à l'Âge $d u$ Fer (VII-Ier siècles avant J.-C.). Cully, Orep Éditions, p. 14.

DESLOGES, J., 2009 - La prospection aérienne dans la plaine de Caen : 1986-2006. In, GIRAUD P. (dir.), Gaulois sous les pommiers, découvertes de l'âge du Fer en Basse-Normandie, $I X^{e}-I^{e r}$ siècle av. J.-C. Cabourg, Conseil Général du Calvados, service d'archéologie; Éditions Cahiers du Temps, p. 12-14. 
DRON, J.-L., 2008 - Un site gaulois à Condé-sur-Ifs. Histoire et Traditions Populaires, 103, p. 21-25.

DRON, J.-L., 2009 - La soue à cochon(s) [le site de Basly]. Le Cochon Truffier, 56, p. 4-7.

FÉRET, L., LE FORESTIER, S., 2009 - Les importations. In, GIRAUD P. (dir.), Gaulois sous les pommiers, découvertes de l'âge du Fer en Basse-Normandie, $I X^{X}-I^{e r}$ siècle av. J.-C. Cabourg, Conseil Général du Calvados, service d'archéologie; Éditions Cahiers du Temps, p. 91-93.

FICHTL, S., 2010 - Réflexions sur les remparts de type Fécamp. In, Murus Celticus : Architecture et fonctions des remparts de l'âge du Fer, (Actes de la Table ronde internationale, 11-12 octobre, 2006, Glux-en-Glenne). Bibracte, 19, p. 315-334.

GIRAUD, P., 2009 - Cagny, exploitations agricoles de la fin du premier âge du Fer (Calvados). Dossier : Normandie celte et romaine. L'Archéologue, Revue d'archéologie et d'histoire, 102, juin-juillet p. 15-16.

GIRAUD, P., 2009 - Loppidum du " Castellier ", SaintDésir/Saint-Pierre-des-Ifs (Calvados). In, GIRAUD P. (dir.), Gaulois sous les pommiers, découvertes de l'âge du Fer en Basse-Normandie, $I X^{e}-I^{\text {er }}$ siècle av. J.-C. Cabourg, Conseil Général du Calvados, service d'archéologie; Éditions Cahiers du Temps, p. 42-45.

GIRAUD, P., 2009 - Nécropole de Fontenay-le-Marmion «La Grande Pièce » (Calvados). In, DELRIEU F. (dir.), Les Gaulois et la mort en Normandie, les pratiques funéraires à l'Âge du Fer (VII-Ier siècles avant J.-C.). Cully, Orep Éditions, p. 33.

GIRAUD, P., RIQUIER, C., BAUDRY-DAUTRY, A., DIETSCH-SELLAMI, M.-F., 2009 - L'habitat Bronze final-Hallstatt ancien de " La Grande Pièce » à Fontenayle-Marmion (Calvados). In, ROULIERE-LAMBERT M.-J., DAUBIGNEY A., MILCENT P.-Y., TALON M., VITAL J. (dir.), De l'Âge du Bronze à l'Âge du Fer en France et en Europe occidentale ( $X^{e}-V I I^{e}$ siècle av. J.-C.) : la moyenne vallée du Rhône aux âges du Fer, (Actes du $\mathrm{XXX}^{\mathrm{e}}$ colloque international de l'AFEAF, Saint-Romainen-Gal, 26-28 mai 2006). Dijon, Société archéologique de l'est, (Revue archéologique de l'est, supplément; 27), p. 493-499.

GIRAUD, P., COULTHARD, N., 2010 - L'Oppidum du Castellier, chef-lieu des Lexovii. Société Historique de Lisieux, 69, p. 75-86.

GOMEZ DE SOTO, J., BOURHIS, J.-R., MARCIGNY, C., MENEZ, Y., RIVALLAIN, J., VERRON, G., 2009 - Pour en finir avec le Bronze final? Les haches à douille de type armoricain en France. In, ROULIERELAMBERT M.-J., DAUBIGNEY A., MILCENT P.-Y., TALON M., VITAL J. (dir.), De l'Âge du Bronze à l'Âge du Fer en France et en Europe occidentale ( $X^{e}-V I I^{e}$ siècle av. J.-C.) : la moyenne vallée du Rhône aux âges $d u$ Fer, (Actes du XXX colloque international de l'AFEAF, Saint-Romain-en-Gal, 26-28 mai 2006). Dijon, Société archéologique de l'est, (Revue archéologique de l'est, supplément; 27), p. 507-512.

GUIHARD, P.-M., 2009 - Les monnaies. In, GIRAUD P. (dir.), Gaulois sous les pommiers, découvertes de l'âge du Fer en Basse-Normandie, IX $X^{e}-I^{\text {er }}$ siècle av. J.-C. Cabourg, Conseil Général du Calvados, service d'archéologie; Éditions Cahiers du Temps, p. 88-90.

HÉRARD, A., 2009 - La série céramique de la Tène moyenne de l'habitat de la "Corneille " à Putot-enBessin (Calvados). Revue Archéologique de l'Ouest, 26, p. 85-103.

HÉRARD, B., 2009 - Saint-Hilaire-le-Châtel : un silo du second Âge du Fer. Cahiers percherons, 179, p. 35-39.

JAHIER, I., 2009 - Creully, "le Clos de l'Epinette " (Calvados). In, GIRAUD P. (dir.), Gaulois sous les pommiers, découvertes de l'âge du Fer en Basse-Normandie, IX" $i^{e r}$ siècle av. J.-C. Cabourg, Conseil Général du Calvados, service d'archéologie; Éditions Cahiers du Temps, p. 26-28.

JAHIER, I., 2009 - Ensemble funéraire de Courseullessur-Mer, "La Fosse Touzé » (Calvados). In, DELRIEU F. (dir.), Les Gaulois et la mort en Normandie, les pratiques funéraires à l'Âge du Fer (VIt'-Ier siècles avant J.-C.). Cully, Orep Éditions, p. 17.

JAHIER, I., 2009 - Evolution des pratiques funéraires. In, GIRAUD P. (dir.), Gaulois sous les pommiers, découvertes de l'àge du Fer en Basse-Normandie, IXe-Ir siècle av. J.-C. Cabourg, Conseil Général du Calvados, service d'archéologie; Éditions Cahiers du Temps, p. 99-103.

JAHIER, I., 2009 - Les bâtiments sur poteaux. In, GIRAUD P. (dir.), Gaulois sous les pommiers, découvertes de l'âge du Fer en Basse-Normandie, IX $X^{e}-T^{r}$ siècle av. J.-C. Cabourg, Conseil Général du Calvados, service d'archéologie; Éditions Cahiers du Temps, p. 31-33.

JAHIER, I., 2009 - Nécropole d'Eterville " Le Clos des Lilas" (Calvados). In, DELRIEU F. (dir.), Les Gaulois et la mort en Normandie, les pratiques funéraires à l'Âge $d u$ Fer (VII-Ier siècles avant J.-C.). Cully, Orep Éditions, p. 10-12.

LE GOFF, E., 2009 - Etude d'un terroir agraire à Ifs (Calvados). In, GIRAUD P. (dir.), Gaulois sous les pommiers, découvertes de l'áge du Fer en Basse-Normandie, $I X^{e}$ $i^{e r}$ siècle av. J.-C. Cabourg, Conseil Général du Calvados, service d'archéologie; Éditions Cahiers du Temps, p. 23-25.

LE GOFF, E., 2009 - Habitats, terroir et paysage rural : aménagement et structuration du territoire et de la campagne gauloise, Ifs, ZAC « Object'Ifs Sud » (Calvados). 
In, BERTRAND I., DUVAL A., GOMEZ DE SOTO J., MAGUER P. (dir.), Habitats et paysages ruraux en Gaule et regards sur d'autres régions du monde celtique, (Actes du XXXI e colloque interrégional de l'Association Française pour l'Étude de l'Âge du Fer, 17-20 mai 2007, Chauvigny - Vienne, F). Chauvigny, Association des publications chauvinoises, (Mémoire XXXV des publications chauvinoises), p. 93-107.

LEFORT, A., MARCIGNY, C., 2009 - La probable agglomération portuaire du second âge du Fer d'UrvilleNacqueville : un état de la documentation. Bulletin de l'AMARAI, 22, p. 39-82.

LEFORT, A., MARCIGNY, C., 2009 - L'artisanat du lignite, Nacqueville (Manche). In, GIRAUD P. (dir.), Gaulois sous les pommiers, découvertes de l'âge du Fer en Basse-Normandie, $I X^{X}-I^{e r}$ siècle av. J.-C. Cabourg, Conseil Général du Calvados, service d'archéologie; Éditions Cahiers du Temps, p. 75-77.

LEFORT, A., MARCIGNY, C., 2009 - Urville, la possible agglomération portuaire d'Urville-Nacqueville (Manche). Dossier : Normandie celte et romaine. L'Archéologue, Revue d'archéologie et d'histoire, 102, juinjuillet p. 23-25.

LEFORT, A., MARCIGNY, C., 2009 - Reprise des études sur le site Âge du Fer d'Urville-Nacqueville : bilan documentaire et perspectives de recherche. In, MARCIGNY C. (dir.), Archéologie, histoire et anthropologie de la presqu'île de la Hague (Manche). Analyse sur la longue durée d'un espace naturel et social cohérent. Quatrième année de recherche, 2008. Beaumont-Hague, p. 62-123.

LEFORT, A., 2010 - Une agglomération portuaire de la Tène finale à Urville-Nacqueville (Manche)?. In, MARCIGNY Cyril (dir.), La Hague dans tous ses états. Archéologie, Histoire, Anthropologie. OREP Éditions, p. 110-111.

LEFORT, A., 2010 - Une communauté gauloise entre terre et Manche : le gisement d'Urville-Nacqueville. Archéopages, 30, juillet, p. 22-25.

LEJARS, T., MÉNIEL, P., PERNET, L., 2009 - Les sanctuaires d'Aunou-sur-Orne et d'Alençon (Orne). In, GIRAUD P. (dir.), Gaulois sous les pommiers, découvertes de l'âge du Fer en Basse-Normandie, IX $X^{e}-T^{\text {er }}$ siècle av. J.-C. Cabourg, Conseil Général du Calvados, service d'archéologie; Éditions Cahiers du Temps, p. 96-98.

LEPAUMIER, H., 2009 - Les tombes à char : un marqueur de « l'aristocratie » gauloise. In, DELRIEU F. (dir.), Les Gaulois et la mort en Normandie, les pratiques funéraires à l'Age du Fer (VII-Ier siècles avant J.-C.). Cully, Orep Éditions, p. 22-23.

LEPAUMIER, H., GIAZZON, D., CHANSON, K., 2009 - Orval «Les Pleines» (Manche) : une tombe à char en
Cotentin. In, DELRIEU F. (dir.), Les Gaulois et la mort en Normandie, les pratiques funéraires à l'Âge du Fer (VIt'Ier siècles avant J.-C.). Cully, Orep Éditions, p. 25-26.

\section{LEPAUMIER, H., BESNARD-VAUTERIN, C.-C., LE}

GOFF, E., 2009 - L'organisation des campagnes gauloises. In, GIRAUD P. (dir.), Gaulois sous les pommiers, découvertes de l'âge du Fer en Basse-Normandie, IX $X^{e}-T^{e r}$ siècle av. J.-C. Cabourg, Conseil Général du Calvados, service d'archéologie; Éditions Cahiers du Temps, p. 20-22.

LEPAUMIER, H., GIAZZON, D., CHANSON, K., 2009 - Orval, une tombe à char, "Les Pleines ", Orval (Manche). Dossier : Normandie celte et romaine. L'Archéologue, Revue d'archéologie et d'histoire, 102, juinjuillet p. 28-30.

LEPAUMIER, H., CORDE, D., 2009 - La généralisation de l'incinération au milieu du Ier siècle avant notre ère : Bricqueville-la-Blouette (Manche). In, DELRIEU F. (dir.), Les Gaulois et la mort en Normandie, les pratiques funéraires à l'Âge du Fer (VIt'-1er siècles avant J.-C.). Cully, Orep Éditions, p. 39-40.

LEPAUMIER, H., DELRIEU, F., 2010 - L'âge du Fer en Basse-Normandie (-800 à -52 av. J.-C.). Bilan de la Recherche 1984-2004. In, Bilan de la Recherche Archéologique Basse-Normandie 1984-2010 : Du Paléolithique à la fin de l'Age du Fer-Vol. I : Préhistoire - Protohistoire. Ministère de la Culture et de la Communication, p. 143-168.

LEPAUMIER, H., 2010 - Cerisé (61), Parc d'Activité, une nécropole tumulaire en périphérie alençonnaise. Bulletin de la Société Historique et Archéologique de l'Orne, CXXIX, 1-2, p. 25-44.

LEROYER, C., BOULEN, M., MARGUERIE, D., LORHO, T., PRAT, B., ARGANT, J., 2009 - Base de données et S.I.G. palynologiques sur l'Âge du Fer en France : une autre approche du paysage végétal et de son anthropisation. In, BERTRAND I., DUVAL A., GOMEZ DE SOTO J., MAGUER P. (dir.), Habitats et paysages ruraux en Gaule et regards sur d'autres régions du monde celtique, (Actes du XXXI ${ }^{e}$ colloque interrégional de l'Association Française pour l'Étude de l'Âge du Fer, 17-20 mai 2007, Chauvigny - Vienne, F). Chauvigny, Association des publications chauvignoises, (Mémoire des publications chauvinoises; XXXV), p. 447-468.

LESPEZ, L., GERMAIN-VALLÉE, C., 2009 L'environnement à l'âge du Fer. In, GIRAUD P. (dir.), Gaulois sous les pommiers, découvertes de l'àge du Fer en Basse-Normandie, $I X^{e}-I^{\text {er }}$ siècle av. J.-C. Cabourg, Conseil Général du Calvados, service d'archéologie; Éditions Cahiers du Temps, p. 15-17. 
MALRAIN, F., BLANCQUAERT, G., LORHO, T., MÉNIEL, P., MATTERNE, V., LEROYER, C., 2009 Un outil pour le renouveau des études sur le monde rural de l'âge du Fer en France : la base de données associée à un SIG. Archéopages, 27, p. 68-77.

MARCIGNY, C., 2009 - Paysages agraires. Dossier : Normandie celte et romaine. L'Archéologue, Revue d'archéologie et d'histoire, 102, juin-juillet p. 17-19.

MATTERNE, V., BOUBY, L., BOUCHETTE, A., CABANIS, M., DERREUMAUX, M., DURAND, F., MARINVAL, P., PRADAT, B., DIETSCH-SELLAMI, M.-F., WIETHOLD, J., 2009 - L'agriculture du $\mathrm{vI}^{\mathrm{e}}$ au $\mathrm{I}^{\mathrm{er}}$ s. av. J.-C. en France. Etat des recherches carpologiques sur les établissements ruraux. In, BERTRAND I., DUVAL A., GOMEZ DE SOTO J., MAGUER P. (dir.), Habitats et paysages ruraux en Gaule et regards sur d'autres régions du monde celtique, (Actes du $\mathrm{XXXI}^{\mathrm{e}}$ colloque interrégional de l'Association Française pour l'Étude de l'Âge du Fer, 17-20 mai 2007, Chauvigny - Vienne, F). Chauvigny, Association des publications chauvinoises, (Mémoire XXV des publications chauvinoises), p. 383-416.

MÉNIEL, P., AUXIETTE, G., GERMINET, D., BAUDRY-DAUTRY, A., HORARD-HERBIN, M.-P., 2009 - Une base de données sur les études de faunes des établissements ruraux en Gaule. In, BERTRAND I., DUVAL A., GOMEZ DE SOTO J., MAGUER P. (dir.), Habitats et paysages ruraux en Gaule et regards sur d'autres régions du monde celtique, (Actes du XXXI colloque interrégional de l'Association Française pour l'Étude de l'Âge du Fer, 17-20 mai 2007, Chauvigny - Vienne, F). Chauvigny, Association des publications chauvinoises, (Mémoire des publications chauvinoises; XXXV), p. 417-446.

NILLESSE, O., 2009 - Activités, métiers, vie quotidienne dans les établissements ruraux de l'Ouest de la France à travers l'instrumentum (Hallstatt D/début du HautEmpire). In, BERTRAND I., DUVAL A., GOMEZ DE SOTO J., MAGUER P. (dir.), Habitats et paysages ruraux en Gaule et regards sur d'autres régions du monde celtique, (Actes du XXXI e colloque interrégional de l'Association Française pour l'Étude de l'Âge du Fer, 17-20 mai 2007, Chauvigny - Vienne, F). Chauvigny, Association des publications chauvinoises, (Mémoire XXXV des publications chauvinoises), p. 45-83.

OUDRY-BRAILLON, S., BILLARD, C., 2009 - Trois sépultures atypiques du Second âge du Fer à Reviers (Calvados). Revue Archéologique de l'Ouest, 26, p. 105115.

SAN JUAN, G., 2009 - L'éperon de "La Campagne " à Basly (Calvados). In, GIRAUD P. (dir.), Gaulois sous les pommiers, découvertes de l'âge du Fer en Basse-Normandie, $I X^{e}-I^{e r}$ siècle av. J.-C. Cabourg, Conseil Général du Calvados, service d'archéologie; Éditions Cahiers du Temps, p. 34-37.

SAN JUAN, G., LE GOFF, I., 2009 - Nécropole de Basly "La Campagne " (Calvados). In, DELRIEU F. (dir.), Les Gaulois et la mort en Normandie, les pratiques funéraires à l'Âge du Fer (VIt-Ir siècles avant J.-C.). Cully, Orep Éditions, p. 15-16.

SAVARY, X., MANSON, A.-L., 2009 - Les céramiques au microscope. In, GIRAUD P. (dir.), Gaulois sous les pommiers, découvertes de l'âge du Fer en Basse-Normandie, IX'$I^{e r}$ siècle av. J.-C. Cabourg, Conseil Général du Calvados, service d'archéologie; Éditions Cahiers du Temps, p. 69-71.

SÉHIER, E., 2009 - La fabrication du textile. In, GIRAUD P. (dir.), Gaulois sous les pommiers, découvertes de l'àge $d u$ Fer en Basse-Normandie, $I X^{e}-I^{\text {er }}$ siècle av. J.-C. Cabourg, Conseil Général du Calvados, service d'archéologie; Éditions Cahiers du Temps, p. 56-59.

SIEVERS, S., 2010 - Die Wallgrabungen von Manching im Vergleich. In, Murus Ceticus : Architecture et fonctions des remparts de l'âge du Fer, (Actes de la Table ronde internationale, 11-12 octobre, 2006, Glux-en-Glenne). Bibracte, 19, p. 175-186.

VILLAREGUT, J., 2009 - Ri, "Le Moulin Foulon " (Orne). In, DELRIEU F. (dir.), Les Gaulois et la mort en Normandie, les pratiques funéraires à l'Âge du Fer (VIt - $I^{e r}$ siècles avant J.-C.). Cully, Orep Éditions, p. 24.

ZAOUR, N., 2009 - Les activités métallurgiques. In, GIRAUD P. (dir.), Gaulois sous les pommiers, découvertes de l'àge du Fer en Basse-Normandie, IXe-Ir siècle av. J.-C. Cabourg, Conseil Général du Calvados, service d'archéologie; Éditions Cahiers du Temps, p. 72-74.

ZECH-MATTERNE, V., 2009 - L'agriculture : stocks de grains archéologiques. In, GIRAUD P. (dir.), Gaulois sous les pommiers, découvertes de l'âge du Fer en BasseNormandie, IX $X^{e}-I^{e r}$ siècle av. J.-C. Cabourg, Conseil Général du Calvados, service d'archéologie; Éditions Cahiers du Temps, p. 51-52.

\section{Gaule romaine}

ANONYME, 2010 - Les musée et sites archéologiques de Vieux-la-Romaine (Calvados). Archéopages, 74, p. 74-77.

BESNARD-VAUTERIN, C.-C., SIMON, L., BERTHELOT, S., CARPENTIER, V., LABAUNEJEAN, F., SÉHIER, E., 2009 - Les établissements gallo-romains. La culture matérielle. In, BESNARDVAUTERIN C.-C. (dir.), En plaine de Caen, une cam- 
pagne gauloise et antique. L'occupation du site de l'Étoile à Mondeville. Rennes, PUR, coll. "Archéologie et Culture », p. 181-206.

BLAIZOT, F., 2009 - Les pratiques et les espaces funéraires dans l'Antiquité. Etat de la recherche, réalités du corpus examiné et orientations du dossier. Gallia, 66.1, p. 1-14.

BOISLÈVE, J., SCHUTZ, G., 2010 - Les peintures murales romaines de la fouille du 51-53 rue de Bretagne à Bayeux (Calvados, Basse-Normandie). Aremorica, 4.

CARPENTIER, V., BESNARD-VAUTERIN, C.-C., 2009 - Les établissements gallo-romains. L'organisation générale des vestiges. In, BESNARD-VAUTERIN C.-C. (dir.), En plaine de Caen, une campagne gauloise et antique. L'occupation du site de l'Etoile à Mondeville. Rennes, PUR, coll. «Archéologie et Culture », p. 163180.

CARPENTIER, V., BESNARD-VAUTERIN, C.-C., 2009Les établissements gallo-romains. Synthèse. L'occupation antique de l'Étoile dans le contexte de la plaine de Caen. In, BESNARD-VAUTERIN C.-C. (dir.), En plaine de Caen, une campagne gauloise et antique. L'occupation du site de l'Étoile à Mondeville. Rennes, PUR, coll. «Archéologie et Culture ", p. 181-212.

CHOLET, L., DELAVAL, E., GUYARD, L., 2010 - La place de la recherche dans l'exploitation des sites antiques normands. In, SAN JUAN G., DELACAMPAGNE F. (dir.), La mise en valeur du patrimoine monumental antique en Normandie, (Actes de la table ronde de Eu - Seine-Maritime, 25-26 novembre 2004). Publications des Universités de Rouen et du Havre, p. 113-119.

DELACAMPAGNE, F., DELAVAL, E., 2010 - Fouilles, recherches et mise en valeur à Vieux (Calvados), antique Aregenua. In, SAN JUAN G., DELACAMPAGNE F. (dir.), La mise en valeur du patrimoine monumental antique en Normandie, (Actes de la table ronde de Eu - Seine-Maritime, 25-26 novembre 2004). Publications des Universités de Rouen et du Havre, p. 73-80.

DELAHAYE, F., FÉRET, L., 2008 - Un lot de céramiques du Haut-Empire dans l'enceinte du collège Notre-Dame à Lisieux. Bulletin de la Société Historique de Lisieux, 66, p. 75-91.

DEROUET, R., 2008 - Le chemin antique de Caen à Exmes. Histoire et Traditions Populaires, 103, p. 49-53.

DUCLOS, C., JEANNE, L., LE GAILLARD, L., PAEZREZENDE, L., 2009 - De nouvelles découvertes sur le sanctuaire gallo-romain de Montaigu-la-Brisette. Bulletin municipal de Montaigu-la-Brisette, 5, 2009. n.p.

DUCLOS, C., JEANNE, L., PAEZ-REZENDE, L., 2009 - Collections gallo-romaines du muséum de Cherbourg. Cherbourg, Muséum Emmanuel Liais, (Collection Unica), 82 p.
GANIVET, M., 2008 - Archéologie : nouveau regard sur le site de Saint-Ouen-de-la-Cour. Cahiers Percherons, 175, 3e trimestre, p. 1-3.

JEANNE, L., FÉRET, L., DUCLOS, C., LE GAILLARD, L., PAEZ-REZENDE, L., 2008 - Une occupation du $\mathrm{I}^{\mathrm{er}}$ siècle de notre ère à Brillevast : Le Hameau Valogne. Revue de la Manche, 50, fasc. 200, p. 29-36.

JEANNE, L., DUCLOS, C., LE GAILLARD, L., PAEZREZENDE, L., SOREL, Y., 2008. - Montaigu-laBrisette, Le Hameau Gréard : d'une petite nécropole gauloise à un habitat gallo-romain, quatre siècles d'occupation rurale en marge de la ville romaine. Revue de la Manche, 50, fasc. 200, p. 60-64.

JEANNE, L., DUCLOS, C., LE GAILLARD, L., PAEZREZENDE, L., 2008 - Une officine de terres cuites architecturales dans le bois de Barnavast, Le Pas du Vivray, commune de Teurthéville-Bocage. Revue de la Manche, 50, fasc. 201, p. 43-48.

JEANNE, L., DUCLOS, C., LE GAILLARD, L., PAEZREZENDE, L., 2008 - Une villa gallo-romaine à Benoistville (Le Plateau). Revue de la Manche, 50, fasc. 200, p. 37-41.

JEANNE, L., DUCLO, S C., LE GAILlARD, L., 2009 - Une villa gallo-romaine à Benoistville (le plateau). Bulletin du groupe de recherches archéologiques $d u$ Cotentin, 13, p. 39-40.

JEANNE, L., FÉRET, L., DUCLOS, C., LE GAILLARD, L., PAEZ-REZENDE, L., 2009 - Une occupation du $\mathrm{I}^{\text {er }}$ siècle de notre ère à Brillevast. Bulletin du groupe de recherches archéologiques du Cotentin, 13, p. 41-43.

JEANNE, L., DUCLOS, C., LE GAILLARD, L., PAEZREZENDE, L., SOREL, Y., 2009 - Montaigu-laBrisette, «Le Hameau Gréard ». D’une petite nécropole gauloise à un habitat gallo-romain : quatre siècles d'occupation rurale en marge d'une ville romaine. Bulletin du groupe de recherches archéologiques du Cotentin, 13, p. 47-49.

JEANNE, L., DUCLOS, C., LE GAILLARD, L., PAEZREZENDE, L., 2009 - Une officine de terres cuites architecturales dans le bois de Barnavast. Bulletin du groupe de recherches archéologiques du Cotentin, 13, p. 44-46.

LABAT, B., GUYARD, L., 2010 - Le musée de site et la valorisation des données. In, SAN JUAN G., DELACAMPAGNE F. (dir.), La mise en valeur $d u$ patrimoine monumental antique en Normandie, (Actes de la table ronde de Eu - Seine-Maritime, 25-26 novembre 2004). Publications des universités de Rouen et du Havre, p. 127-131.

LECLERC, G., 2008 - Le sanctuaire gallo-romain de Macé (Orne). L'Archéologue, Archéologie nouvelle, 94, p. 32-34. 
LE GAILLARD, L., DUCLOS, C., JEANNE L., PAEZREZENDE, L., 2008 - Montaigu-la-Brisette : fouilles archéologiques - campagne 2007. Bulletin municipal de Montaigu-la-Brisette, 4, n.p.

LE GAILLARD, L., DUCLOS, C., JEANNE, L., PAEZREZENDE, L., 2009 - Un édifice thermal gallo-romain à Montaigu-la-Brisette. Bulletin municipal de Montaigula-Brisette, 5, n.p.

LEMAITRE, C., 2009 - La colonne votive de Lisieux. Bulletin de la Société Historique de Lisieux, 67, p. 23-91.

LEMAITRE, C., 2010 - Essai sur l'administration de la Civitas Lexoviorum pendant la seconde moitié du $\mathrm{I}^{\mathrm{er}}$ siècle avant J.-C. Histoire et Traditions Populaires, 111, p. 63-76.

LEVALET D., 2010 - Avranches et la cité des Abrincates ( ${ }^{e r}$ siècle avant J.-C.-VII siècle après J.-C.) : recherches historiques et archéologiques. Société des Antiquaires de Normandie, (Mémoires de la Société des Antiquaires de Normandie, XLV), $262 \mathrm{p}$.

MALIGORNE, Y., 2009 - Contribution des ordres d'architecture à la différenciation des espaces. Quelques exemples gaulois. Aremorica, 3, p. 87-112.

OUZOULIAS, P., 2010 - Les campagnes gallo-romaines : quelle place pour la villa?. In, OUZOULIAS P., TRANOY L. (dir.), Comment les Gaules devinrent romaines. Paris, La Découverte, p. 189-211.

PAILLARD, D., ALDUC-LE AGOUSSE, A., BUCHET, L., BLONDIAUX, J., NIEL, C., 2009 - Identité sociale ou miroir d'une société en évolution? Les tombes remarquables de la seconde moitié du IVe siècle dans la nécropole Michelet à Lisieux (Calvados). In, Première table ronde du Cinquantenaire du CRAHM "Inhumations de prestige ou prestige de l'inhumation. Expressions du pouvoir dans l'au-delà", Caen, 23-24 mars 2007.

PECHOUX, L., 2010 - Les sanctuaires de périphérie urbaine en Gaule Romaine. Montagnac : Editions Monique Mergoil, (Archéologie et Histoire Romaine, 18), 500 p.

QUÉVILLON, S., 2010 - Le patrimoine monumental antique en Basse-Normandie. In, SAN JUAN G., DELACAMPAGNE F. (dir.), La mise en valeur du patrimoine monumental antique en Normandie, (Actes de la table ronde de Eu - Seine-Maritime, 25-26 novembre 2004). Publications des Universités de Rouen et du Havre, p. 29-36.

SCHUTZ, G., 2010 - L'artisanat antique dans le chef-lieu de cité de Vieux Aregenua (Calvados). In, CHARDRONPICAULT P. (dir.), Aspects de l'artisanat en milieu urbain, Gaule et Occident romain, (Actes du colloque international d'Autun, 20-22 septembre 2007). Dijon, (Revue Archéologique de l'Est, suppl. 28), p. 95-107.
SUMÉRA, F., avec la coll. de PRIGENT, D., 2009 - Les matières premières. In, COUTELAS A. (dir.), Le Mortier de chaux. Paris, Éditions Errance, p. 33-74.

WELLS, C., 2009 - La bataille de Normandie (56 av. J.-C.). Revue de l'Avranchin et du Pays de Granville, 86, fasc. 419 , p. 165-175.

ZECH-MATTERNE, V., 2010 - Le développement de la fructiculture en Gaule du Nord, à l'époque romaine. In, OUZOULIAS P., TRANOY L. (dir.), Comment les Gaules devinrent romaines. Paris, La Découverte, p. 255266.

\section{7. ÉPOQUe MÉDIÉVALE}

BAYLÉ, M., 2008 - Le tombeau du chevalier Hugues dans l'église de Troarn. Bulletin de la Société des Antiquaires de Normandie, LXV, (2002-2003). p. 11-18.

BAYLÉ, M., 2008 - Les parties romanes de l'église du Plessis-Grimoult : $165^{\mathrm{e}}$ Congrès de Condé-sur-Noireau, 2007. Annuaire des cinq Départements de la Normandie, p. 15-20.

BECK, B., 2008 - Compte-rendu des visites de mai à juillet : l'abbaye d'Hambye. Revue de l'Avranchin et du Pays de Granville, 85, fasc. 416, p. 308-315.

BERNAGE, G., 2010 - Le château de la Rivière. Patrimoine Normand, 74, p. 14-19.

BERNAGE, G., 2010 - Les premières églises de nos ducs. Patrimoine Normand, 73, p. 25-43.

BERTHELOT, S., WAVELET, T., 2010 - Les ampoules de pèlerinage d'Eculleville. In, MARCIGNY Cyril (dir.), La Hague dans tous ses états. Archéologie, Histoire, Anthropologie. OREP Éditions, p. 124-125.

BILLARD, C., BERNARD, V., 2009 - Basse-Normandie (Manche et Calvados). Domaine public maritime. Chronique des fouilles médiévales en France en 2008. Archéologie Médiévale, 39, p. 338-339.

BILLARD, C., 2010 - Basse-Normandie (Manche et Calvados). Domaine public maritime. Chronique des fouilles médiévales en France en 2009. Archéologie Médiévale, 40, p. 335.

BOCQUET-LIÉNARD, A., FICHET DE CLAIRFONTAINE, F., 2008 - Lieusaint (Manche). Ferme de la Fosse : une officine de production céramique médiévale $\left(\mathrm{XI}^{\mathrm{e}}-\mathrm{XII}^{\mathrm{e}} \mathrm{s}\right.$.). Chroniques des fouilles médiévales en France en 2007. Archéologie Médiévale, 38, p. 295.

BOCQUET-LIÉNARD, A., FLAMBARD-HÉRICHER, A.-M. 2009 - La vaisselle céramique en Normandie du XIV ${ }^{\mathrm{e}}$ au XVI ${ }^{\mathrm{e}}$ siècle et le PCR Typochronologie de la céramique bas-normande $\mathrm{x}^{\mathrm{e}}$-XVI ${ }^{\mathrm{e}}$ siècle. In, RAVOIRE 
(F.), DIETRICH (A.) (dir.), La cuisine et la table dans la France de la fin du Moyen Age, contenus et contenants du $X I V^{v}$ au XVI siècle, (Actes du colloque de Sens, 8-10 janvier 2004). Caen, Publications du CRAHM, p. 215-235.

BOUVRIS, J.-M., 2008 - chartes du prieuré de Rouvrou, dépendance de l'abbaye de Fontenay, à l'ancien diocèse de Bayeux (XII ${ }^{\mathrm{e}}$-XIII ${ }^{\mathrm{e}}$ siècles) : $165^{\mathrm{e}}$ Congrès de Condésur-Noireau, 2007. Annuaire des cinq Départements de la Normandie, p. 193-222.

BROINE, E., 2008 - Cherbourg-Octeville (Manche). Abbaye Notre-Dame-du-Vœu. Chroniques des fouilles médiévales en France en 2007. Archéologie Médiévale, 38, p. 210-211.

BROWN, R., 2009 - Falaise (Calvados). Château, bastion nord-est. Chronique des fouilles médiévales en France en 2008. Archéologie Médiévale, 39, p. 259.

BÜTTNER, S., PRIGENT, D., 2010 - Les matériaux de construction dans le bâtiment médiéval. In, Trente ans d'Archéologie Médiévale en France : un bilan pour l'avenir. (IX ${ }^{\mathrm{e}}$ congrès international de la Société d'archéologie médiévale, Vincennes, 16-18 juin 2006). Caen, Publications du CRAHM, p. 179-194.

CANU, B., 2008 - Les ports fluviaux du seuil du Cotentin. In, Sur la route de Louviers. Voies de communication et moyens de transport de l'Antiquité à nos jours, (Actes du 42e congrès des Sociétés historiques et archéologiques de Normandie). Louviers, (Congrès des sociétés historiques et archéologiques de Normandie; 13), p. 271-290.

CARDON, T., 2008 - Le trésor de Saint-Fraimbaultsur-Pisse et la circulation monétaire dans le sud de la Normandie vers 1200. Le Domfrontais médiéval, 20, (2008-2009), p. 23-36.

CARPENTIER, V., 2008 - Habitat paysan et vie quotidienne aux portes d'Argentan, à travers quelques données archéologiques récentes ( $\mathrm{XI}^{\mathrm{e}}$-XII ${ }^{\mathrm{e}}$ siècles). In, MOULIN M.-A., CHAVE I., FAJAL B., FOUCHER J.-P. (dir.), Argentan et ses environs au Moyen Âge : approche historique et archéologique, (Actes de la journée d'études, Argentan, 29 mars 2003). Alençon, Conseil général de l'Orne, Publications du CRAHM, p. 55-79.

CARPENTIER, V., 2008 - Les " seigneurs du marais » : regard sur l'encadrement des hommes au bord des marais de la Dives (Calvados) : châteaux, maisons fortes, manoirs et prieurés, $\mathrm{XI}^{\mathrm{e}}$-XVIII ${ }^{\mathrm{e}}$ siècles. In, LALOU E., LEPEUPLE B., ROCH J.-L. (dir.), Des châteaux et des sources, archéologie et histoire dans la Normandie médiévale : mélanges en l'honneur d'Anne-Marie FlambardHéricher. Mont-Saint-Aignan, PURH, p. 223-254.

CARPENTIER, V., 2009 - Fontenai-sur-Orne (Orne). Les Fresneaux. Chronique des fouilles médiévales en France en 2008. Archéologie Médiévale, 39, p. 185-186.
CARPENTIER, V., 2009 - Giberville (Calvados). Delle de derrière l'église. Chronique des fouilles médiévales en France en 2008 (sépultures et nécropoles). Archéologie Médiévale, 39, p. 310.

CARPENTIER, V., 2009 - Giberville (Calvados). Delle de derrière l'Église. Chronique des fouilles médiévales en France en 2008 (constructions et habitats civils). Archéologie Médiévale, 39, p. 186-187.

CARPENTIER, V., GIAZZON, D., MARCIGNY, C., 2009 - Aspects de la vie domestique et agricole médiévale aux confins de la Normandie et du Maine : Le site d'Arçonnay "Parc Saint-Gilles » (Sarthe) autour du $\mathrm{XII}^{\mathrm{e}}$ siècle. Revue Archéologique de l'Ouest, 26, p. 229258.

CARPENTIER, V., FAJAL, B., FOUCHER, J.-P., 2010 La gestion des ressources piscicoles de l'abbaye de SaintEvroult au XviII ${ }^{e}$ siècle. Bulletin de la Société Historique et Archéologique de l'Orne, CXXIX, 3, p. 81-104.

CARRÉ, G., DUJARDIN, L., LE ROUX, F., MOULIN, M.-A., 2008 - Chambois : exploration et datation d'une fosse médiévale dans la tour-maitresse. Bulletin Monumental, 166-IV, p. 350-353.

CARRÉ, G., 2009 - Chambois (Orne). Fosse médiévale du donjon. Chronique des fouilles médiévales en France en 2008. Archéologie Médiévale, 39, p. 272.

CARRÉ, F., HINCKER, V., MAHÉ, N., PEYTREMANN, E., POIGNANT, S., ZADORA-RIO, E., 2009 Histoire(s) de(s) village(s) : l'archéologie en contexte villageois, un enjeu pour la compréhension de la dynamique des habitats médiévaux. Les Nouvelles de l'Archéologie, 116, p. 51-59.

CARRÉ, G., 2010 - Douvres-la-Délivrande (Calvados). La Baronnie. Chronique des fouilles médiévales en France en 2009. Archéologie Médiévale, 40, p. 224.

CASSET, M., 2008 - Inventaires après décès et archéologie des séjours nobles: données croisées dans la Normandie médiévale. In, LALOU E., LEPEUPLE B., ROCH J.-L. (dir.), Des châteaux et des sources, archéologie et histoire dans la Normandie médiévale: mélanges en l'honneur d'Anne-Marie Flambard-Héricher. Mont-Saint-Aignan, PURH, p. 341-351.

CASSET, M., 2008 - Le manoir épiscopal de Douvresla-Délivrande. Bulletin de la Société des Antiquaires de Normandie, LXV, (2002-2003). p. 19-24.

CASSET, M., 2010 - Les évêques d'Avranches dans leurs murs au Moyen âge, à Saint-Philbert-sur-Risle et au Parc. Revue de l'Avranchin et du Pays de Granville, 87, fasc. 424, p. 366-372.

CAZIN, V., 2009 - Découverte de graffiti dans l'église de Vaucelles (Calvados). Haute-Normandie archéologique, 14, p. 167-172. 
CHAPELOT, J., GENTILI, F., 2010 - Trente ans d'archéologie médiévale en France. In, CHAPELOT J. (dir.), Trente ans d'Archéologie Médiévale en France : un bilan pour l'avenir. (IX congrès international de la Société d'archéologie médiévale, Vincennes, 16-18 juin 2006). Caen, Publications du CRAHM, p. 3-24.

CHAVE, I., CORVISIER, C., DESLOGES, J., 2008 - Le château d'Argentan $\left(\mathrm{XI}^{\mathrm{e}}-\mathrm{XV}^{\mathrm{e}}\right.$ siècle $)$ : du castrum roman à la résidence princière. In, MOULIN M.-A., CHAVE I., FAJAL B., FOUCHER J.-P. (dir.), Argentan et ses environs au Moyen Âge: approche historique et archéologique: actes de la journée d'études, Argentan, 29 mars 2003. Alençon, Conseil général de l'Orne, p. 115-206.

CORMIER, J.-P., 2008 - Notre-Dame-sur-l'Eau de Domfront : une mise au point sur son histoire, son architecture et son décor. In, BARRÉ É. (dir.), La paroisse en Normandie au Moyen Age : la vie paroissiale, l'église et le cimetière, (Actes du colloque de Saint-Lô, Archives départementales de la Manche, 28-30 novembre 2002). Saint-Lô, Société d'archéologie et d'histoire de la Manche, p. 261-277.

CORVISIER, C., 2008 - Le château de Condé-surNoireau : $165^{\mathrm{e}}$ Congrès de Condé-sur-Noireau, 2007. Annuaire des cinq Départements de la Normandie, p. 29-36.

COULTHARD, N., DELACAMPAGNE, F., HINCKER, V., SAVARY, X., 2009 - Les pavés de l'abbaye de SaintEvroult (Orne). In, CHAPELOT J., CHAPELOT O., RIETH B. (dir.), Terres cuites architecturales médiévales et modernes en Ile-de-France et dans les régions voisines. Caen, Publications du CRAHM, p. 267-281.

CUCHE, J.-L., 2010 - La vie d'une femme résolue, au $\mathrm{xx}^{\mathrm{e}}$ siècle, dans une abbaye. Revue de l'Avranchin et $d u$ Pays de Granville, 87, fasc. 422, p. 55-100.

DECAËNS, H., 2008 - Petite histoire du Mont-SaintMichel. Études normandes, 4, p. 4-22.

DECAËNS, J., DUBOIS, A., 2009.- Le château de Caen. 1000 ans d'une forteresse dans la ville. Caen, Publications du CRAHM, $128 \mathrm{p}$.

DELACAMPAGNE, F., SAVARY, X. MANEUVRIER, C., ALDUC-LEBAGOUSSE, A., 2008 - Evrecy : de l'église abbatiale à l'église paroissiale (VIII ${ }^{\mathrm{e}}$-XIV ${ }^{\mathrm{e}}$ siècles). In, BARRÉ E. (dir.), La paroisse en Normandie au Moyen Age : la vie paroissiale, l'église et le cimetière, (Actes du colloque de Saint-Lô, Archives départementales de la Manche, 28-30 novembre 2002). Saint-Lô, Éditions de la Société d'archéologie et d'histoire de la Manche, (Études et Documents; 27), p. 355-383.

DELACAMPAGNE, F., MANEUVRIER, C., 2008 - Des figures de défunts sur céramique : la diffusion des platestombes en Normandie (XIII $-\mathrm{XVII}^{\mathrm{e}}$ siècles). In, LALOU
E., LEPEUPLE B., ROCH J.-L. (dir.), Des châteaux et des sources, archéologie et histoire dans la Normandie médiévale: mélanges en l'honneur d'Anne-Marie FlambardHéricher. Mont-Saint-Aignan, PURH, p. 575-612.

DELACAMPAGNE, F., SAVARY, X., 2009 - Bayeux : une plaque de chancel carolingien. Actualités, Calvados. Bulletin Monumental, 167-4, p. 357-358.

DELAHAYE, F., 2008 - La motte castrale de Blangy-leChâteau : recherches archéologiques récentes. Bulletin de la Société Historique de Lisieux, 66, p. 58-74.

DELAHAYE, F., 2009 - Portbail (Manche). Abords du baptistère. Chronique des fouilles médiévales en France en 2008. Archéologie Médiévale, 39, p. 305.

DELAHAYE, F., NIEL, C., 2009 - Thaon (Calvados). Église Saint-Pierre. Chronique des fouilles médiévales en France en 2008. Archéologie Médiévale, 39, p. 235-236.

DELAHAYE, F., NIEL, C., 2010 - Thaon (Calvados). Église Saint Pierre. Chronique des fouilles médiévales en France en 2009. Archéologie Médiévale, 40, p. 240.

DELAHAYE, F., 2010 - Alençon (Orne). Rue de l'Abreuvoir, institut "La Providence ». Chronique des fouilles médiévales en France en 2009. Archéologie Médiévale, 40, p. 251.

DELAHAYE, F., 2010 - Juaye-Mondaye (Calvados). Abbaye Saint-Martin. Chronique des fouilles médiévales en France en 2009. Archéologie Médiévale, 40, p. 226.

DESCHAMPS, Y., 2009 - Le manoir de Carel à SaintMichel-de-Livet. Histoire et Traditions Populaires, 107, p. 51-60.

DESFORGES, J.-D., 2009 - L'histoire d'un site, le MontRomigny, nécropole mérovingienne du Perche ornais. Cahiers percherons, 177, p. 25-35.

DESHAYES, J., 2008 - Châteaux, seigneuries et voies de communication du Cotentin médiéval. In, Sur la route de Louviers. Voies de communication et moyens de transport de l'Antiquité à nos jours, (Actes du 42e congrès des Sociétés historiques et archéologiques de Normandie). Louviers, (Congrès des sociétés historiques et archéologiques de Normandie; 13), p. 65-80.

DESHAYES, J., 2008 - Structures murales et phases de construction : la première génération des églises du Cotentin. In, BARRÉ E. (dir.), La paroisse en Normandie au Moyen Age : la vie paroissiale, l'église et le cimetière, (Actes du colloque de Saint-Lô, Archives départementales de la Manche, 28-30 novembre 2002). Saint-Lô, Société d'archéologie et d'histoire de la Manche, (Études et Documents; 27), p. 278-297.

DESHAYES, J., 2008 - Le logis seigneurial de la Motte à Angoville-sur-Ay. Revue de la Manche, 50, fasc. 201, p. 23-33. 
DESHAYES, J., 2009 - La Chapelle Saint-Germain de Querqueville : un édifice phare de l'érudition normande. 166e Congrès de Cherbourg et de la Hague, 2008. Annuaire des cinq départements de la Normandie, tiré à part, p. 117-150.

DESHAYES, J., 2009 - L'église Saint-Martin d'Octeville. 166e Congrès de Cherbourg et de La Hague, 2008. Annuaire des cinq départements de la Normandie, tiré à part, p. 151-159.

DESHAYES, J., 2010 - L'archéologie du bâti : l'exemple de Vauville, église paroissiale Saint-Martin. In, MARCIGNY Cyril (dir.), La Hague dans tous ses états. Archéologie, Histoire, Anthropologie. OREP Éditions, p. 128-129.

DUBOIS, J., 2010 - Saint-Germain de Cerisé, étude historique, archéologique et artistique. Bulletin de la Société Historique et Archéologique de l'Orne, CXXIX, 1-2, p. 45-82.

DUCOEUR, D., 2009 - Sous les anciens pavements de la nef restituée de l'abbaye de La Lucerne. Revue de l'Avranchin et du Pays de Granville, 86, fasc. 420, p. 235-277.

DUCOEUR, D., 2010 - La restitution du bâtiment conventuel sud - cellier et réfectoire - de l'abbaye de La Lucerne. Revue de l'Avranchin et du Pays de Granville, 87, fasc. 424, p. 279-336.

DUGUÉ M.-L., 2010 - Le site du manoir épiscopal. Revue de l'Avranchin et du Pays de Granville, 87, fasc. 424, p. 383-387.

DUHAULT, L., 2008 - La paroisse et la seigneurie de Merville de l'Antiquité à la fin de l'Ancien Régime. Bulletin de la Société des Antiquaires de Normandie, LXV, (2002-2003), p. 25-46.

EPAUD, F., 2008 - Le « mur armé » : quelques exemples de raidissements architectoniques en bois de murs maçonnés dans l'architecture militaire normande du XII au XIV siècle. In, LALOU E., LEPEUPLE B., ROCH J.-L. (dir.), Des châteaux et des sources, archéologie et histoire dans la Normandie médiévale: mélanges en l'honneur d'Anne-Marie FlambardHéricher. Mont-Saint-Aignan, PURH, p. 255-273.

FLAMBARD-HÉRICHER, A.-M., 2008 - La Pommeraye (Calvados), Château Ganne. Chroniques des fouilles médiévales en France en 2007. Archéologie Médiévale, 38, p. 255-256.

FLAMBARD-HÉRICHER, A.-M., 2008 - Le Château Ganne : premiers résultats de la fouille archéologique. Publications du CRAHM, $129 \mathrm{p}$.

FLAMBARD-HÉRICHER, A.-M., 2008 - Le château Ganne à La Pommeraye (Calvados) : bilan des recherches 2004-2007 : 165 Congrès de Condé-sur-Noireau, 2007. Annuaire des cinq Départements de la Normandie, p. 127154.
FLAMBARD-HÉRICHER, A.-M., LEPEUPLE, B., 2008

- Topographie et prospection : une approche renouvelée de l'étude des châteaux 1980-2006. In, ETTEL P., FLAMBARD-HÉRICHER A.-M., MCNEILL T. E (dir.), Château Gaillard: bilan des recherches en castellologie, (Actes du 23e colloque international, Houffalize (Belgique), 4-10 sept. 2006). Caen, Publications du CRAHM, (Château Gaillard, 23), p. 189-204.

FLAMBARD-HÉRICHER, A.-M. 2009 - Le Château Ganne à La Pommeraye à l'époque de la bataille de Tinchebray d'après les premières découvertes archéologiques. In, GAZEAU (V.), GREEN (J.) (dir.), Tinchebray 1106-2006, (Actes du colloque de Tinchebray, 28-30 septembre 2006). Le Pays Bas-Normand, 271-272, (2008). p. 123-138.

FLAMBARD-HÉRICHER, A.-M. 2009 - Note sur les aménagements des cuisines dans quelques fortifications normandes du XI ${ }^{\mathrm{e}}$ au XIII ${ }^{\mathrm{e}}$ siècle. In, BOUET P., BOUGY Catherine, GARNIER Bernard, MANEUVRIER Christophe (dir.), De part et d'autre de la Normandie médiévale. Recueil d'études en hommage à François Neveux. Cahiers des Annales de Normandie, 35, p. 83-95.

FLAMBARD-HÉRICHER, A.-M. 2009 - Pommeraye (La) (Calvados). Le Château Ganne. Chronique des fouilles médiévales en France en 2008. Archéologie Médiévale, 39, p. 286-288.

FLAMBARD-HÉRICHER, A.-M. BOCQUETLIÉNARD, A., 2009 - Basse-Normandie. PCR « Typochronologie de la céramique médiévale dans l'espace bas-normand du Xe $\mathrm{x}^{\mathrm{e}} \mathrm{XVI}^{\mathrm{e}}$ siècle. Production, diffusion ». Chronique des fouilles médiévales en France en 2008. Archéologie Médiévale, 39, p. 323.

FLAMBARD-HÉRICHER, A.-M., BOCQUETLIÉNARD, A., 2010 - Basse-Normandie. PCR "Typochronologie de la céramique médiévale dans l'espace bas-normand du $\mathrm{x}^{\mathrm{e}}-\mathrm{XVI}^{\mathrm{e}}$ siècle. Production, diffusion ». Chronique des fouilles médiévales en France en 2009. Archéologie Médiévale, 40, p. 319-320.

FLAMBARD-HÉRICHER, A.-M., BOCQUETLIÉNARD, A., 2010 - La poterie de grès normande : une production aux dimensions de l'Europe. In, ARNOUX M., FLAMBARD-HÉRICHER A.-M. (dir.), La Normandie dans l'économie européenne (XII'-XVIf siècle), (Actes du colloque de Cerisy-la-Salle, 4-8 octobre 2006). Caen, Publications du CRAHM, p. 179-199.

FLAMBARD-HÉRICHER, A.-M., 2010 - Entre légende et réalité : le vrai visage du Château Ganne ( $\mathrm{La}$ Pommeraye, Calvados). In, ETTEL P. FLAMBARDHÉRICHER A-M. MCNEILL T.E. (dir.), Études de castellologie médiévale, (Actes du colloque international de Stirling (Écosse), 30 août-5 septembre 2008). 
Publications du CRAHM, (Château Gaillard, 24), p. 93-103.

FLAMBARD-HÉRICHER, A.-M., 2010 - La Pommeraye (Calvados). Château Ganne. Chronique des fouilles médiévales en France en 2009. Archéologie Médiévale, 40, p. 275-278.

GALLET, Y., LE GOFF, M., 2008 - L'étude archéomagnétique du four de la rue de la poterie à Argentan : quarante ans après. In, MOULIN M.-A., CHAVE I., FAJAL B., FOUCHER J.-P. (dir.), Argentan et ses environs au Moyen Âge : approche historique et archéologique, (Actes de la journée d'études, Argentan, 29 mars 2003). Alençon, Conseil général de l'Orne, p. 259-265.

GORET, J.-F., POPLIN, F., avec la coll. de MANEUVRIER, C., 2008 - Trois pièces d'échecs en ivoire de morse découvertes au château de Crèvecoeuren-Auge (Calvados). Archéologie Médiévale, 38, p. 61-69.

GROUD-CORDRAY, C., 2009 - Le Val de Mortain. Morphologie et rôles d'un espace frontière entre Normandie, Bretagne et Maine, $\mathrm{x}^{\mathrm{e}}$ siècle-début XIII ${ }^{\mathrm{e}}$ siècle. In, GAZEAU (V.), GREEN (J.) (dir.), Tinchebray 1106-2006, (Actes du colloque de Tinchebray, 28-30 septembre 2006). Le Pays BasNormand, 271-272, (2008). p. 189-206.

HARDUIN-AUBERVILLE, G., 2008 - Saint-Arnoult : la chapelle prieurale et l'église paroissiale. Le Pays d'Auge, 58e année, 1, p. 35-38.

HELYE, D., 2010 - L'église de Saint-Martin-le-Vieux, de Bréhal, notes historiques et archéologiques. Bulletin de la Société des Antiquaires de Normandie, 68, (2009). p. 147169.

HINCKER, V., 2008 - Le cimetière mérovingien de Manerbe : reflet d'une petite communauté rurale du $\mathrm{vII}^{\mathrm{e}}$ siècle. Bulletin de la Société Historique de Lisieux, 66, p. 93-128.

HINCKER, V., 2008 - Vieux (Calvados). Chemin des Gaudines. Chroniques des fouilles médiévales en France en 2007. Archéologie Médiévale, 38, p. 201.

HINCKER, V., POIRIER, A., 2008 - Manerbe (Calvados). Saint-Sauveur. Chroniques des fouilles médiévales en France en 2007. Archéologie Médiévale, 38, p. 282.

HINCKER, V., 2008 - Vieux (Calvados). Place SaintMartin. Chroniques des fouilles médiévales en France en 2007. Archéologie Médiévale, 38, p. 291.

HINCKER, V., 2009 - Falaise (Calvados). Vâton. Chronique des fouilles médiévales en France en 2008. Archéologie Médiévale, 39, p. 317-318.

HINCKER, V., 2010 - Banneville-la-Campagne (Calvados). Chemin Saulnier. Chronique des fouilles médiévales en France en 2009. Archéologie Médiévale, 40, p. 303-304.
HINCKER, V., 2010 - Falaise (Calvados). Vâton. Chronique des fouilles médiévales en France en 2009. Archéologie Médiévale, 40, p. 308.

JAMBU, J., 2010 - La circulation des monnaies étrangères en Normandie, du milieu du $\mathrm{XIV}^{\mathrm{e}}$ au milieu du XVIIe siècle : un révélateur d'une économie mondialisée?. In, ARNOUX M., FLAMBARD-HÉRICHER A.-M. (dir.), La Normandie dans l'économie européenne (XII-XVII siècle), (Actes du colloque de Cerisy-la-Salle, 4-8 octobre 2006). Publications du CRAHM, p. 19-38.

JEAN-MARIE, L., 2008 - Des maisons au château : le château de Caen, une paroisse urbaine. In, LALOU E., LEPEUPLE B., ROCH J.-L. (dir.), Des châteaux et des sources, archéologie et histoire dans la Normandie médiévale: mélanges en l'honneur d'Anne-Marie FlambardHéricher. Mont-Saint-Aignan, PURH, p. 377-388.

JEANNE, D., 2008 - La léproserie Sainte-Marie-Madeleine d'Argentan : une approche historique et archéologique. In, MOULIN M.-A., CHAVE I., FAJAL B., FOUCHER J.-P. (dir.), Argentan et ses environs au Moyen Age : approche historique et archéologique, (Actes de la journée d'études, Argentan, 29 mars 2003). Alençon, Conseil général de l'Orne, p. 97-114.

JUHEL, V., 2008 - Aperçu sur les anciennes voies de communication de la région de Condé-sur-Noireau : $165^{\mathrm{e}}$ Congrès de Condé-sur-Noireau, 2007. Annuaire des cinq Départements de la Normandie, p. 7-12.

JUHEL V., 2008 - Les églises de Condé-sur-Noireau : $165^{\mathrm{e}}$ Congrès de Condé-sur-Noireau, 2007. Annuaire des cinq Départements de la Normandie, p. 23-28.

JUHEL, V., 2008 - L'église de Vassy : 165 Congrès de Condé-sur-Noireau, 2007. Annuaire des cinq Départements de la Normandie, p. 75-78.

JUHEL, V., 2008 - Eglises rurales : $165^{\mathrm{e}}$ Congrès de Condésur-Noireau, 2007. Annuaire des cinq Départements de la Normandie, p. 87-90.

JUHEL, V., 2008 - Rouvrou : $165^{\mathrm{e}}$ congrès de Condésur-Noireau. Annuaire des cinq Départements de la Normandie, p. 117-118.

LAILLIER, J.-Y., 2008 - Autour de la destruction du donjon de Domfront : nouveaux éclairages sur les vicissitudes du château (vers 1574-1611). Le Domfrontais médiéval, 20, (2008-2009). p. 43-48.

LANGLOIS, J.-Y., GALLIEN, V., 2009 - Le souple dans tous ses états : de l'espace colmaté à l'espace vide. In, BIZOTB., SIGNOLI M. (dir.), Rencontres autour des sépultures habillées, (Actes des journées d'études organisées par le Groupement d'Anthropologie et d'Archéologie funéraire et le Service Régional de l'Archéologie de PACA, Carry-le-Rouet (13), 13-14 décembre 2008). MCC, GAAF, p. 13-20. 
LASSEUR, G., 2008 - La destruction de la Porte d'Alençon. Le Domfrontais médiéval, 20, (2008-2009). p. 39-42.

LECLERC-KEROULLÉ, A., 2008 - Le château de Chanteloup. Patrimoine Normand, 67, p. 8-16.

LECGER, D., 2008 - L'église paroissiale du PlessisGrimoult : 165e Congrès de Condé-sur-Noireau, 2007. Annuaire des cinq Départements de la Normandie, p. 13-14.

LECGER, D., 2008 - L'enceinte fortifiée du PlessisGrimoult : 165e Congrès de Condé-sur-Noireau, 2007. Annuaire des cinq Départements de la Normandie, p. 21-22.

LE GAILLARD, L., 2009 - Saint-Contest (Calvados). Espace Entreprise. Chronique des fouilles médiévales en France en 2008. Archéologie Médiévale, 39, p. 195.

LE MAHO, J., 2010 - Quelques remarques sur la genèse de la ville de Caen. Bulletin de la Société des Antiquaires de Normandie, 68, (2009), p. 171-199.

LEPELTIER, C., 2010 - Ouilly-le-Tesson (Calvados). Le Manoir. Chronique des fouilles médiévales en France en 2009. Archéologie Médiévale, 40, p. 274.

LEPETIT-VATTIER, J., 2008 - Un chemin seigneurial de Bricquebec : "La Querrière Bertrand ». In, Sur la route de Louviers. Voies de communication et moyens de transport de l'Antiquité à nos jours, (Actes du $42^{\mathrm{e}}$ congrès des Sociétés historiques et archéologiques de Normandie). Louviers, (Congrès des sociétés historiques et archéologiques de Normandie; 13), p. 81-89.

LE PROVOST, G., 2010 - Corvées, droits et redevances seigneuriales à Chérencé-le-Héron. Revue de l'Avranchin et du Pays de Granville, 87, fasc. 423, p. 147-200.

LEROUX, N., 2008 - Réflexions sur les pêcheries fluviomaritimes médiévales dans la basse vallée de la Seine. In, LALOU E., LEPEUPLE B., ROCH J.-L. (dir.), Des châteaux et des sources, archéologie et histoire dans la Normandie médiévale : mélanges en l'honneur d'AnneMarie Flambard-Héricher. Mont-Saint-Aignan, PURH, p. 129-141.

LEROY, B., 2008 - Un Tremissis mérovingien découvert à Torchamp (Orne). Le Domfrontais médiéval, 20, (20082009). p. 37-38.

LEVARD, H., 2009 - La chapelle de Saint-Quentin-d'Elle à Bérigny (Manche). Revue de la Manche, t. 51, fasc. 204, p. 18-46.

LITOUX, E., CARRÉ, G., 2008 - Manoirs médiévaux : maisons habitées, maisons fortifiées. Paris, Rempart, (Patrimoine vivant), $157 \mathrm{p}$.

MARCIGNY, C., 2010 - Colomby (Manche). Sablière de Flottemanville-Bocage. Chronique des fouilles médiévales en France en 2009. Archéologie Médiévale, 40, p. 328.
MASTROLORENZO, J., 2008 - Falaise (Calvados). Château, fossé est et rampe d'accès. Chroniques des fouilles médiévales en France en 2007. Archéologie Médiévale, 38, p. 246-247.

MASTROLORENZO, J., HANACHI, S., 2009.- Falaise (Calvados). Le château. Chronique des fouilles médiévales en France en 2008. Archéologie Médiévale, 39, p. 276-278.

MASTROLORENZO, J., HANACHI, S., 2010 - Falaise (Calvados). Château de Falaise. Chronique des fouilles médiévales en France en 2009. Archéologie Médiévale, 40, p. 266.

MORAND, F., ZAOUR, N., GIRAULT, N., 2009 Archéologie en forêt de Bellême : une activité métallurgique du haut Moyen Âge. Cahiers percherons, 179, p. 30-34.

NEVEUX, F., 2008 - Les églises du Mont-Saint-Michel : de la crypte au sanctuaire de hauteur. In, LALOU E., LEPEUPLE B., ROCH J.-L. (dir.), Des châteaux et des sources, archéologie et histoire dans la Normandie médiévale: mélanges en l'honneur d'Anne-Marie FlambardHéricher. Mont-Saint-Aignan, PURH, p. 517-527.

NEVEUX, F., 2010 - Les agglomérations castrales en Normandie ( $\mathrm{xI}^{\mathrm{e}}-\mathrm{XV}^{\mathrm{e}}$ siècle). In, CHEDEVILLE A., PICHOT D. (dir.), Des villes à l'ombre des châteaux : naissance et essor des agglomérations castrales en France au Moyen Âge, (Actes du colloque de Vitré - 16-17 octobre 2008). PUR, coll. "Archéologie et Culture », p. 141152.

NISSEN-JAUBERT, A., 2009 - Le château de Domfront de la fin du XIe siècle au milieu du XII ${ }^{\mathrm{e}}$ siècle. Les vestiges archéologiques et leur contexte historique. In, GAZEAU (V.), GREEN (J.) (dir.), Tinchebray 1106-2006, (Actes du colloque de Tinchebray, 2006). Le Pays Bas-Normand, 271-272, (2008). p. 139-155.

OEIL DE SALEYS, S., 2008 - Lestre (Manche). Chapelle Saint-Michel. Chroniques des fouilles médiévales en France en 2007. Archéologie Médiévale, 38, p. 215-216.

PIERRE, M.-J., 2009 - L'église Saint-Martin-des-Champs (Argentan, Orne) : peintures murales et guerres de religion. Haute-Normandie archéologique, 14, p. 173-182.

RAJADE, A., 2009 - Fonction des "grosses perles de ceinture ", éléments de parure ou objets fonctionnels? In, L'actualité de l'archéologie du haut Moyen Âge en Picardie, Les apports de l'expérimentation à l'archéologie mérovingienne, (Actes des XXIX Journées internationales d'archéologie mérovingienne, musée des Temps Barbares, Marle (Aisne), 26-28 septembre 2008). Revue Archéologique de Picardie, 1-2, p. 77-86.

RENOUX, A., 2010 - Châteaux, palais et habitats aristocratiques fortifiés et semi-fortifiés. In, CHAPELOT 
J. (dir.), Trente ans d'Archéologie Médiévale en France: un bilan pour l'avenir. (IX congrès international de la Société d'archéologie médiévale, Vincennes, 16-18 juin 2006). Caen, Publications du CRAHM, p. 239-256.

RIDEL, E., 2009 - Les Vikings et les mots. Paris, Éditions Errance, $351 \mathrm{p}$.

RIDEL, E., 2010 - La Hague, un coin du monde Viking? Aperçu critique sur la question. In, MARCIGNY Cyril (dir.), La Hague dans tous ses états. Archéologie, Histoire, Anthropologie. OREP Éditions, p. 120-121.

RIDEL, E., 2010 - Les Navires de la Conquête : construction navale et navigation en Normandie à l'époque de Guillaume Le Conquérant. OREP Éditions, 63 p.

ROSE, Y., 2008 - A l'origine de la ville d'Alençon : le pont de Sarthe ( $\mathrm{xI}^{\mathrm{e}}-\mathrm{xx}^{\mathrm{e}}$ siècles). In, Sur la route de Louviers. Voies de communication et moyens de transport de l'Antiquité à nos jours : actes du 42e congrès des Sociétés historiques et archéologiques de Normandie. Louviers, (Congrès des sociétés historiques et archéologiques de Normandie; 13), p. 151-159.

ROSEL (DU), G., 2008 - Saint-Germain-du-Crioult, la motte féodale : 165e Congrès de Condé-sur-Noireau, 2007. Annuaire des cinq Départements de la Normandie, p. 83-86.

RUAS, M.-P., 2010 - Des grains, des fruits et des pratiques : la carpologie historique en France. In, CHAPELOT J. (dir.), Trente ans d'Archéologie Médiévale en France: un bilan pour l'avenir. (IX ${ }^{\mathrm{e}}$ congrès international de la Société d'archéologie médiévale, Vincennes, 16-18 juin 2006). Caen, Publications du CRAHM, p. 55-70.

SADY, M., 2009 - Vieux-Pont-en-Auge : une très vieille histoire. Histoire et Traditions Populaires, 108, p. 43-47.

SAINT-JAMES, F., NICOLAS-MÉRY, D., LEVALET, D., 2009 - Montchaton et Orval : compte rendu des visites de février, mars et avril 2009. Revue de l'Avranchin et $d u$ Pays de Granville, 86, fasc. 419, p. 203-232.

SAINT-JAMES, F., 2010 - L'église Saint-Cyr et SainteJulitte à Saint-Cyr-du-Bailleul. Revue de l'Avranchin et du Pays de Granville, 87, fasc. 424, p. 406-408.

SAPIN, C., BAYLÉ, M., BÜTTNER, S., GUIBERT, P., BLAIN, S., LANOS, P., CHAUVIN, A., DUFRESNE, P., OBERLIN, C., 2008 - Archéologie du bâti et archéométrie au Mont-Saint-Michel, nouvelles approches de Notre-Dame-Sous-Terre. Archéologie médiévale, 38, p. 71-122.

TONQUEDEC (de), E., 2010 - L'abbaye de Montmorel à Poilley. Revue de l'Avranchin et du Pays de Granville, 87, fasc. 424, p. 389-393.

VASTEL, J., 2008 - L'abbaye du Vou "près Chierebourg ". Éditions Ville de Cherbourg-Octeville, (Unica), 96 p.
VIGOT, A.-S., HINCKER, V., 2010 - La salle capitulaire de l'abbaye de Saint-Evroult-Notre-Dame-du-Bois : l'apport de l'archéologie. Bulletin de la Société Historique et Archéologique de l'Orne, CXXIX, 3, p. 67-80.

\section{8. ÉPOQUES MODERNE ET CONTEMPORAINE}

ANONYME, 2009 - Le Village du Mont-Saint-Michel. Patrimoine Normand, 72, p. 6-22.

BERNAGE, G., 2009 - Bayeux, autour de l'Hôtel du Doyen. Patrimoine Normand, 71, p. 38-43.

BERNAGE, G., 2009 - Crosville-sur Douve. Patrimoine Normand, 71, p. 24-31.

BERNAGE, G., 2009 - Bayeux, la rue Saint-Jean. Patrimoine Normand, 72, p. 42-47.

BERNAGE, G., 2010 - Le Spitfire de la baie de Sallenelles. Patrimoine Normand, 76, p. 24-31.

BERNOUIS, P., FAJAL, B., 2008 - Aux marges du Bessin potier, l'atelier de Jurques et ses productions de grès aux $\mathrm{XIX}^{\mathrm{e}}$-Xx ${ }^{\mathrm{e}}$ siècles. In, LALOU É., LEPEUPLE B., ROCH J.-L. (dir.), Des châteaux et des sources, archéologie et histoire dans la Normandie médiévale : mélanges en l'honneur d'Anne-Marie Flambard-Héricher. Mont-Saint-Aignan, PURH, p. 87-102.

BLANCHARD, L., LELIÈVRE, P., 2008 - Les ingénieurs du Roi au chevet du port de Honfleur, du grand tournant du règne de Louis XIV à la fin de l'Ancien Régime. Le Pays d'Auge, 58e année, 1, p. 24-24.

BLOND, S., 2008 - Les routes normandes au XVIII ${ }^{\mathrm{e}}$ siècle d'après l'Atlas de Trudaine. In, Sur la route de Louviers. Voies de communication et moyens de transport de l'Antiquité à nos jours, (Actes du 42e congrès des Sociétés historiques et archéologiques de Normandie). Louviers, (Congrès des sociétés historiques et archéologiques de Normandie; 13), p. 91-101.

BOUVIER DES NOËS, F., 2009 - Buré, village percheron. Cahiers percherons, 178, p. 43-62.

DESHAYE, S J., 2009 - Le Logis seigneurial de la Motte à Angoville-sur-Ay. Bulletin du groupe de recherches archéologiques du Cotentin, 13, p. 54-57.

DUFOUR, M., 2010 - Naufrages et épaves le long des côtes du pays haguard. In, MARCIGNY Cyril (dir.), La Hague dans tous ses états. Archéologie, Histoire, Anthropologie. OREP Éditions, p. 144-145.

DUGUÉ, M.-L., 2010 - L'église de Sainte-Pience. Revue de l'Avranchin et du Pays de Granville, 87, fasc. 424, p. 381382.

DUHAULT, L., FERAUGE, M., 2008 - La redoute de Merville-Franceville-Plage. Bulletin de la Société des Antiquaires de Normandie, LXV, (2002-2003), p. 47-54. 
DUTEURTRE, C., 2008 - Château de Servigny : une demeure historique. Patrimoine Normand, 66, p. 11-23.

DUTEURTRE, C., 2008 - Château du Pont-Rilly : le XVIII ${ }^{\mathrm{e}}$ siècle à l'honneur. Patrimoine Normand, 67, p. 17-25.

FOSSE, G., VILGRAIN-BAZIN, G., 2010 - Archéologie et ethnohistoire des périodes moderne et contemporaine. In, MARCIGNY C. (dir.), La Hague dans tous ses états. Archéologie, Histoire, Anthropologie. OREP Éditions, p. $130-145$.

GARNIER, R., 2008 - La redoute de Merville 1762-2007. Le Pays d'Auge, 58 année, 2, p. 7-14.

GELINEAU, J.-C., 2009 - La forge et le fourneau de Carrouges au XIx ${ }^{e}$ siècle. Bulletin de la Société Historique et Archéologique de l'Orne, 128, 1er trim. p. 5-52.

GIRET, J.-M., 2009 - Le four banal de Saint-Lambert à Neuilly-la-Forêt. Patrimoine Normand, 69, p. 10-11.

HOUILLIER, S., 2009 - Led-Heu, un fort dans la lande. In, MARCIGNY C. (dir.), Archéologie, histoire et anthropologie de la presquîle de la Hague (Manche). Analyse sur la longue durée d'un espace naturel et social cohérent. Quatrième année de recherche, 2008. Beaumont-Hague, p. 130-143.

HUET, C., 2008 - Urbanisme et clergé à Bayeux au XVIII ${ }^{\mathrm{e}}$ siècle. Bulletin de la Société des Antiquaires de Normandie, LXV (2002-2003), p. 77-93.

LAURENT, K., 2008 - L'habitat paysan dans la région de Saint-Sever-Calvados. Examen architectural et social. Bulletin de la Société des Antiquaires de Normandie, LXV (2002-2003), p. 95-106.

LEVALET, D., 2010 - Quand un cèdre s'abat. (un dépotoir des XVIIe et XviII ${ }^{\mathrm{e}}$ siècles au Jardin des Plantes d'Avranches). Revue de l'Avranchin et du Pays de Granville, 87, fasc. 425, p. 705-716.

LORIEUX, J.-C., 2008 - Les pêcheries du Mont-SaintMichel. Au Fil de la Normandie, 20, p. 53.

MANEUVRIER, J., 2008 - La journée " manoirs " du 31 août 2008. Histoire et Traditions Populaires, 103, p. 26-41.

MANNEVILLE, P., 2008 - le cimetière privé protestant de La Motte à Athis (Orne) : $165^{\mathrm{e}}$ congrès de Condésur-Noireau, 2007. Annuaire des cinq Départements de la Normandie, p. 104-106.

MARIE, E., 2010 - Ethnologie et patrimoine de pays : l'exemple de la pêche à pied dans la Hague. In, MARCIGNY C. (dir.), La Hague dans tous ses états. Archéologie, Histoire, Anthropologie. OREP Éditions, p. 146-158.

MARIE, E., VILGRAIN-BAZIN, G., 2010 - Les viviers à crustacés à la pointe de la Hague. Le Viquet, 170, p. $15-22$.
MORAND, F., QUÉVILLON, S., avec la coll. de ARNAUD, J.-L., 2010 - Prospection archéologique en massif de Réno-Valdieu : une activité métallurgique séculaire. Cahiers percherons, 183, p. 55-64.

NICOLAS-MÉRY, D., 2010 - Le manoir de l'Aumoire à Morigny. Revue de l'Avranchin et du Pays de Granville, 87, fasc. 422, p. 19-53.

NICOLAS-MÉRY, D., 2010 - Le manoir de Mirande à Saint-Laurent-de-Terregatte. Revue de l'Avranchin et du Pays de Granville, 87, fasc. 424, p. 393-401.

NICOLAS-MÉRY, D., 2010 - Visite du bourg et des manoirs de Saint-Cyr-du-Bailleul. Revue de l'Avranchin et du Pays de Granville, 87, fasc. 424, p. 409-421.

PLAIDEUX, H. (Dr), 2010 - Le prieuré de Saint-Germaindes-Vaux. In, MARCIGNY Cyril (dir.), La Hague dans tous ses états. Archéologie, Histoire, Anthropologie. OREP Éditions, p. 122.

SÉNÉCHAUT, P., 2008 - Les quatre cents ans du château de Villers-sur-Mer. Le Pays d'Auge, 58e année, 6, p. 35-41.

SIMON, C., 2009 - La briqueterie du Porribet. Bulletin du groupe de recherches archéologiques du Cotentin, 13, p. 58-60.

VILGRAIN-BAZIN, G., 2009 - Ham (Le). Manoir de Sigosville. Chronique des fouilles médiévales en France en 2008. Archéologie Médiévale, 39, p. 200.

VILGRAIN-BAZIN, G., 2009 - Havre de « Bombec » : un ancien magasin à soude. Bulletin du groupe de recherches archéologiques du Cotentin, 13, p. 63-64.

VILGRAIN-BAZIN, G., 2009 - Note sur les corps de garde du canton de Beaumont-Hague. In, MARCIGNY C. (dir.), Archéologie, histoire et anthropologie de la presqu'île de la Hague (Manche). Analyse sur la longue durée d'un espace naturel et social cohérent. Quatrième année de recherche, 2008. Beaumont-Hague, p. 124-129.

VILGRAIN-BAZIN, G., HOUILLIER, S., 2010 - LedHeu, un fort dans la Lande. In, MARCIGNY C. (dir.), La Hague dans tous ses états. Archéologie, Histoire, Anthropologie. OREP Éditions, p. 143.

VILGRAIN-BAZIN, G., 2010 - La pêcherie de SaintGermain-des-Vaux. In, MARCIGNY C. (dir.), La Hague dans tous ses états. Archéologie, Histoire, Anthropologie. OREP Éditions, p. 158.

VILGRAIN-BAZIN, G., 2010 - Le moulin à vent du hameau Danneville. In, Bulletin communal de SaintGermain-des-Vaux. p. 27-28.

VILGRAIN-BAZIN, G., 2010 - Les viviers en roche des côtes de la Hague. In, MARCIGNY C. (dir.), La Hague dans tous ses états. Archéologie, Histoire, Anthropologie. OREP Éditions, p. 150-151. 